\title{
Source-to-sink transport of sugar and regulation by environmental factors
}

\author{
Remi Lemoine ${ }^{1 *}$, Sylvain La Camera ${ }^{1}$, Rossitza Atanassova ${ }^{1}$, Fabienne Dédaldéchamp ${ }^{1}$, Thierry Allario ${ }^{1}$, \\ Nathalie Pourtau ${ }^{1}$, Jean-Louis Bonnemain ${ }^{1}$, Maryse Laloi ${ }^{1}$, Pierre Coutos-Thévenot ${ }^{1}$, \\ Laurence Maurousset ${ }^{1}$, Mireille Faucher ${ }^{1}$, Christine Girousse ${ }^{2}$, Pauline Lemonnier ${ }^{1}$, \\ Jonathan Parrilla ${ }^{1}$ and Mickael Durand ${ }^{1}$
}

' Unités Mixtes de Recherche, Ecologie et Biologie des Interactions, Université of Poitiers/Centre National de la Recherche Scientifique, Poitiers, France

${ }^{2}$ Diversité et Ecophysiologie des Céréales, Unités Mixtes de Recherche, Clermont Ferrand, France

\section{Edited by:}

John William Patrick, The University of

Newcastle, Australia

Reviewed by:

John William Patrick, The University of Newcastle, Australia

Aart Van Bel, Justus-Liebig-University Giessen, Germany

*Correspondence:

Remi Lemoine, Unités Mixtes de Recherche, Ecologie et Biologie des Interactions, Université of

Poitiers/Centre National de la Recherche Scientifique, Bâtiment B31, 3 rue Jacques Fort, Poitiers, 86022 Cedex, France

e-mail: remi.lemoine@univ-poitiers.fr
Source-to-sink transport of sugar is one of the major determinants of plant growth and relies on the efficient and controlled distribution of sucrose (and some other sugars such as raffinose and polyols) across plant organs through the phloem. However, sugar transport through the phloem can be affected by many environmental factors that alter source/sink relationships. In this paper, we summarize current knowledge about the phloem transport mechanisms and review the effects of several abiotic (water and salt stress, mineral deficiency, $\mathrm{CO}_{2}$, light, temperature, air, and soil pollutants) and biotic (mutualistic and pathogenic microbes, viruses, aphids, and parasitic plants) factors. Concerning abiotic constraints, alteration of the distribution of sugar among sinks is often reported, with some sinks as roots favored in case of mineral deficiency. Many of these constraints impair the transport function of the phloem but the exact mechanisms are far from being completely known. Phloem integrity can be disrupted (e.g., by callose deposition) and under certain conditions, phloem transport is affected, earlier than photosynthesis. Photosynthesis inhibition could result from the increase in sugar concentration due to phloem transport decrease. Biotic interactions (aphids, fungi, viruses...) also affect crop plant productivity. Recent breakthroughs have identified some of the sugar transporters involved in these interactions on the host and pathogen sides. The different data are discussed in relation to the phloem transport pathways. When possible, the link with current knowledge on the pathways at the molecular level will be highlighted.

Keywords: Phloem, sugar transport, source/sink, abiotic factors, biotic factors

\section{SUGAR TRANSPORT IN THE PHLOEM}

Among the sugars synthesized in a plant, only a few are transported in the phloem over a long-distance, whatever the species and the type of phloem loading considered. In all cases, sucrose is the main form of carbon found in the phloem. In addition to sucrose, polyols (mainly sorbitol and mannitol) and oligosaccharides of the raffinose family can also be found. In some species, both polyols and raffinose are found in the phloem (Rennie and Turgeon, 2009). Hexose transport in the phloem has also been reported for a limited number of species (van Bel and Hess, 2008) but these results were recently challenged (Liu et al., 2012). Raffinose and other members of the raffinose family oligosaccharides are indirectly involved in the building up of sugar concentrations in the phloem by polymer trapping (Rennie and Turgeon, 2009). Conversely, polyols tend to behave exactly like sucrose as far as transport is concerned and thus, in apoplastic loaders, there are specific polyol transporters (Noiraud et al., 2001b). Unless stated otherwise, sucrose is the main sugar we deal with in the following sections.

According to many studies, up to $80 \%$ of photosynthetic fixed carbon can be exported by mature leaves. The amount of sucrose available for export from source leaves depends on several parameters: photosynthetic activity (carbon fixation), partitioning between starch synthesis in the chloroplast and triose-phosphates exported from the chloroplast for sucrose synthesis, and transient storage of sucrose in the vacuole (Figure 1). If one of these factors is altered, the amount of sucrose available for export is affected and therefore source/sink relationships can be altered. The pathways for sucrose loading in the conducting cells of the phloem have been documented mostly in the case of active phloem loading in herbaceous species (Figure 1). Active phloem loading results in a higher solute concentration in the sieve element-companion cell complex (SE/CC complex) than in the surrounding tissues. The mechanism of active phloem loading from the apoplastic space involves sucrose and polyol transporters that have been identified in numerous species (Noiraud et al., 2001b; Lalonde et al., 2004; Sauer, 2007; Reinders et al., 2012). These transporters can concentrate sugars in the SE/CC complex by dissipating the proton gradient established by an $\mathrm{H}^{+}$/ATPase located in the same cells. The release of sucrose in the apoplast in the vicinity of the SE/CC complex may be controlled by the recently discovered SWEET facilitators (Chen et al., 2012; Figure 1). The second mechanism for active phloem loading is polymer trapping, whereby sucrose is converted to raffinose or larger molecules through addition of galactose to sucrose in 


\section{Source leaf}

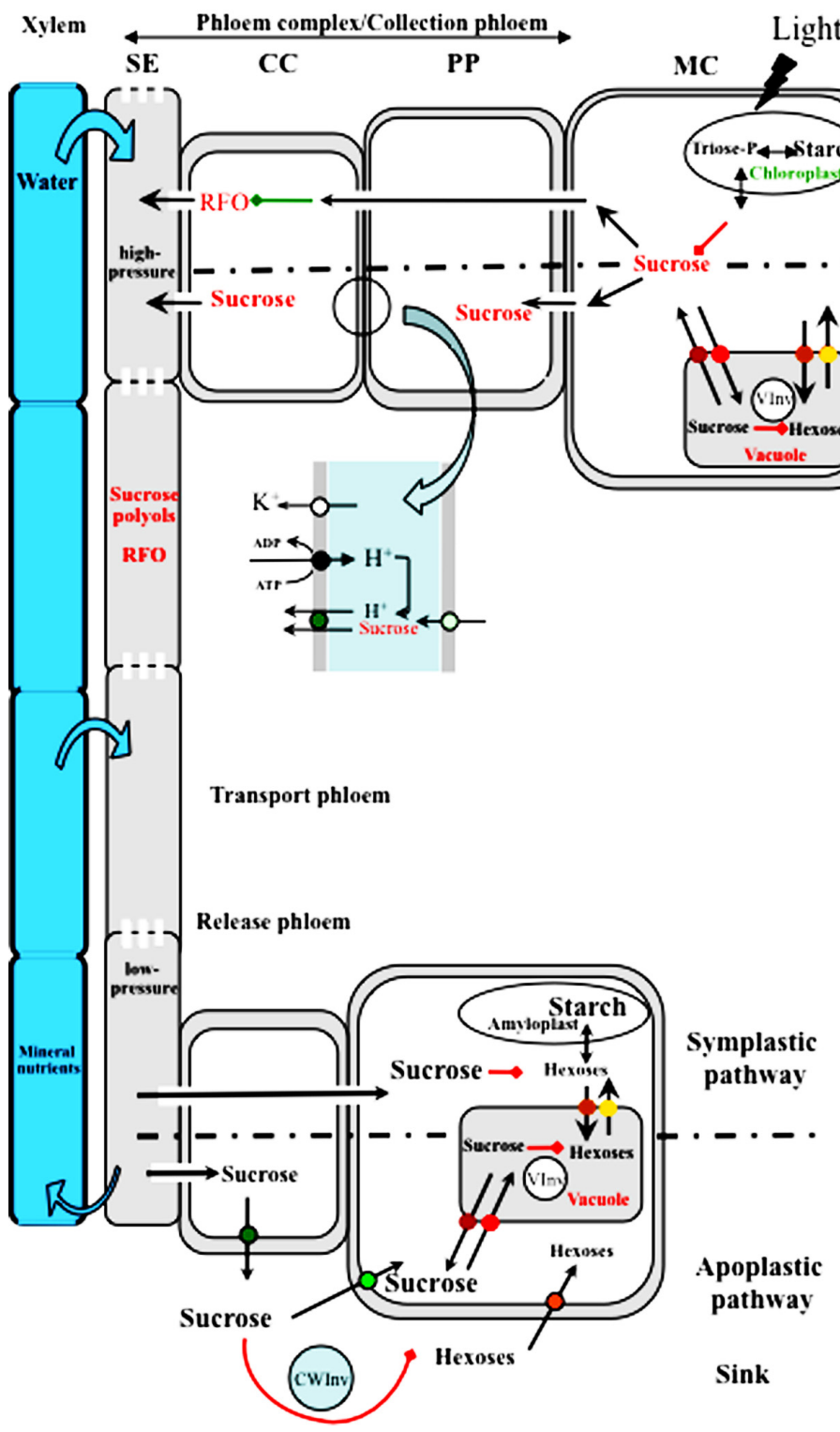

FIGURE 1 | Comparison of source-to-sink sugar transport in symplastic and apoplastic active phloem loaders. Sucrose available for export from mesophyll cells (MC) results from a balance between storage in the vacuoles and sequestration as starch in the chloroplasts. Sucrose can reach the sieve tubes through plasmodesmata that allow for its diffusion from cell to cell in species like cucurbits. Sucrose is converted to larger molecules (RFOs) by the sequential addition of galactosyl residues in modified companion cells (CC) called intermediary cells. The larger molecules cannot move back to phloem parenchyma cells (PP) and are transferred and accumulated in sieve tubes. In apoplast-loading species, sucrose reaches phloem parenchyma cells through plasmodesmata. Sucrose is loaded and accumulates in the phloem by passing through the apoplast between the PP and the CC. The major players are presented in the enlargement of that area. Sucrose enters the apoplast through facilitators of the SWEET family (pale green circle) and is accumulated in the companion cell by a proton/sucrose co-transporter of the SUT1/SUC2 type (green circle). The energy necessary for the co-transport is provided by an $\mathrm{H}+$ /pumping ATPase (black circle) which establishes a proton gradient and a trans-membrane potential regulated by potassium channels of the AKT2/3 type (white circle). In Solanaceous species, SUT1 transporters are localized at the plasma membrane of sieve elements (not shown). Polyols can also be transported into the phloem, with specific transporters located in the plasma membrane of CC (not shown). A high hydrostatic pressure is generated in the sieve tubes of the collection phloem and water from the xylem is attracted. Sucrose, RFOs and polyols are transported in the sieve tubes to the sink organs in the transport phloem. All along the path, they can be leaked from and reloaded into the phloem via the same mechanism (not shown). Sucrose is unloaded into the release phloem where the hydrostatic pressure is supposed to be lower. Sucrose can be unloaded through a symplastic pathway or through an apoplastic pathway. In the latter case, sucrose is unloaded into the apoplast through specific carriers which can be of the SUT1/SUC2 type (green circle; Carpaneto et al., 2005). Sucrose is then taken up by sink-specific sucrose carriers of the same SUT1/SUC2 (light green circle) or converted to hexoses by a cell-wall invertase (CWInv). Hexoses are then taken up by specific carriers at the plasma membrane (orange circle) or at the tonoplast level (yellow and brown circles). Sucrose in sink cells can be metabolized (growing sinks) or stored as starch in amyloplasts, or imported into the vacuoles (red circles) and further converted to hexoses by a vacuolar invertase (VInv). 
intermediary cells (Rennie and Turgeon, 2009). In that case, sugars move from cell to cell through a symplastic pathway (Figure 1). Active phloem loading may not be universal as there are many indications of passive loading at least in tree species (Rennie and Turgeon, 2009; Turgeon, 2010b). This is achieved by maintaining high solute concentrations in the mesophyll cells of such species.

These different pathways concern the loading of sucrose in the so-called collection phloem (Van Bel, 2003) which represents the initial step of long-distance transport. Transport along the path between source and sink occurs in the transport phloem and sucrose is delivered to sink organs by the release phloem (Van Bel, 2003). The most widely accepted concept to explain solute transport in the phloem is mass-flow, as initially proposed by Münch and followers, whereby the hydrostatic pressure difference in the phloem between source (high pressure) and sink (low pressure) accounts for sap movement (Figure 1). At many stages along the pathway, specific transporters are involved in the cell-to-cell movement of sucrose or in the intracellular compartmentation between the cytoplasm and organelles; they thus represent major regulators of sugar fluxes. It should be noted that sucrose transporters (SUTs) have been localized and characterized in the three phloem sections. Sucrose can act as a signal and regulate many genes involved in growth and development (Koch, 2004; Muller et al., 2011).

During longitudinal transport, sucrose can be leaked and retrieved but also used by sink cells along the path (axial sinks; Minchin and Thorpe, 1987). In some species, stems or petioles can be turned into storage organs (e.g., celery; Noiraud et al., 2001a) and this function is even more pronounced in tree trunks (Hou, 1985). In such conditions, storage is transient as resources will later be used to support growth along with plant development. These organs successively act as sinks and sources (Juchaux-Cachau et al., 2007). Concerning their ability to retrieve sucrose from the apoplast, the respective membrane potential levels between SEs and phloem parenchyma cells are decisive (Hafke et al., 2005). SUTs are involved in sucrose movement in the transport phloem, even in tree species where loading is symplastic in the collection phloem (Turgeon, 2010b).

In the release phloem, sugars can exit the phloem through either a symplastic or an apoplastic pathway, although the first steps are often symplastic (Fisher and Oparka, 1996; Patrick, 1997). However, unloading pathways depend on the particular sink involved and its development stage (Figure 1). In sinks like developing seeds or infected tissues, symplastic discontinuity requires an apoplastic step for the transfer of photo-assimilates. A switch from apoplastic to symplastic unloading was noted during potato tuberization (Viola et al., 2001). In fruit development, contrasting results have been found: in grape berry, Zhang et al. (2006) demonstrated a shift from symplastic to apoplastic unloading whereas in apple and cherry fruit there is evidence for an apoplastic step in sucrose and sorbitol unloading, involving transporters (Gao et al., 2003; Zhang et al., 2004).

In seeds, SUTs but also hexose transporters and cell-wall invertases are responsible for sugar movement but their respective roles differ depending on the development stage (Weber et al., 1997; Weschke et al., 2003). These pathways have been extensively studied in legume seeds, together with the corresponding regulation of sucrose unloading (Zhang et al., 2007).

\section{SOURCE-SINK RELATIONSHIPS IN PLANT AND SUGAR ALLOCATION (SINK STRENGTH)}

Sink organs depend on the delivery of sucrose (or other forms of carbohydrates) by the phloem for their growth and development. A plant may be regarded as a series of sources and sinks with an overall carbon fixation capacity and several sinks "competing" for the available photo-assimilates. This creates a priority system among sinks. Roots and young leaves are major sinks during the early developmental stages, whereas tubers, fruit and seeds become major sinks during the reproductive stages (Wardlaw, 1990). The distribution of resources among sinks is also a key factor of plant productivity based on the harvest index (HI). The $\mathrm{HI}$ is the ratio of harvested dry weight over plant dry weight (or above-ground shoot dry weight): therefore a high $\mathrm{HI}$ indicates that a large amount of photo-assimilates has been diverted to the sinks harvested by humans (Gifford et al., 1984).

In order for plants to reach a balanced development and optimize their reproductive fitness, priority for access to photoassimilates needs to be established between sinks. Changes in carbon partitioning and switches between the apoplastic and symplastic pathways occur throughout development or as a response to the environment (Roitsch, 1999; Godt and Roitsch, 2006). Concerning the apoplastic pathway, hexose transport resulting from cell-wall invertase/hexose transporter activity has been suggested to predominate in the sink tissues that undergo cell division and elongation, while sucrose transport predominates in the sink tissues that switch to storage mode (Weschke et al., 2000, 2003).

Priority among sinks has been related to the so-called "sink strength" (Ho, 1988) or sink dominance. According to Wardlaw (1990), the underlying basis of sink strength (assuming a pressure flow mechanism for translocation) is an ability to effectively lower the concentration of photo-assimilates in the SEs of the sinks and thus establish a favorable hydrostatic pressure gradient between the source and the sink. In that respect, the role of cell-wall invertases has frequently been highlighted in sink organs as they increase sucrose unloading by converting sucrose to hexoses. Transport of photo-assimilates depends on source supply and sink demand. The role of the phloem sap sugar content in the coupling between sink demand and source activity is still a matter of debate (Minchin et al., 2002). However, high sucrose contents in leaves could have an inhibitory effect on SUT activity and thus inhibit sucrose loading into the phloem. This point was evidenced by feeding sucrose to the transpiration stream of cut sugar-beet leaves (Chiou and Bush, 1998). The authors hypothesized that high sucrose concentrations in the vascular tissue, resulting from decreased sink demand, down-regulated transporter activity. This could lead to decreased phloem loading and increased sugar levels in mesophyll cells, and in turn down-regulated photosynthesis. The opposite regulation is thought to occur in the case of increased sink demand (Chiou and Bush, 1998). This link between sugar export in leaves and sink demand has been re-examined by Ainsworth and Bush (2011) and phloem sucrose transport has been identified as a possible target for improving plant productivity. 
Phloem transport capacity may not be a limiting factor, as shown in several reports. In transgenic sugarcane, expressing a sucrose isomerase led to the accumulation of sucralose in addition to sucrose in stalk vacuoles. The sugar concentration was therefore doubled in the juice harvested from stalks (Wu and Birch, 2007). In such plants, photosynthesis and sucrose transport were greatly increased, indicating a release of sink limitation. The overexpression of an Arabidopsis tonoplastic glucose transporter (TMT1) led to increased glucose contents in the vacuoles of mesophyll cells and to higher seed yield. In these plants, higher expression levels of AtSUC2, the transporter that loads sucrose into the phloem in Arabidopsis, have been noted (Wingenter et al., 2010). However, TMT1 can also drive sucrose entry into the vacuole (Schulz et al., 2011) and therefore the former interpretation may have to be reconsidered. In rice, when the expression of a SUTs involved in sucrose efflux from the vacuole (OsSUT2) was suppressed, seed production as well as root growth were reduced, indicating that sucrose transport to sinks was impaired (Eom et al., 2011) and confirming the former results obtained in Arabidopsis. Altogether these different data suggest a link between the sugar concentration in the cytoplasm of mesophyll cells and the export of sucrose, and indicates source-limitation in wild-type plants.

Taking the former elements into account, source-to-sink sucrose transport can be affected by environmental factors at least at three different levels (Figure 1):

(i) the source (e.g., by an effect on photosynthesis or phloem loading), resulting in less sucrose available for export,

(ii) the sink (e.g., increased demand for root growth, pathogens developing on plant organs), leading to a new balance between sinks that can be detrimental to yield,

(iii) the path between source and sink (by e.g., cold treatment, aphids, viruses) leading to impaired sucrose delivery.

Plants undergo large changes in their environment throughout their life and have developed many strategies to respond to these changes. The following sections will try to summarize some of the effects of environmental factors on sucrose transport from source to sink organs.

\section{EFFECTS OF ABIOTIC FACTORS}

Among the many environmental factors that can affect plant growth, the present review concentrates on two types: environmental cues and some air and soil pollutants.

\section{EFFECTS OF ENVIRONMENTAL CUES \\ Effects of water deficit}

Water deficit is a major abiotic factor affecting crop development and yield. Drought imposes unfavorable conditions on the leaves (source) and roots (sink) of a plant. However, as pointed out by Turgeon (2010a), the high osmotic potential in the phloem can be a positive parameter for attracting water to the sieve tubes and maintaining phloem sap flow in drought conditions.

Under mild water deficit, shoot growth is restricted while root growth continues and, consequently, plant architecture is modified. In dicots, e.g., pea and grape, the number of branches and the number of leaves on branches are particularly sensitive to soil water deficit (Lecoeur et al., 1995; Lebon et al., 2006). In monocots such as grasses, the number of young emerging organs is reduced under drought (Courtois et al., 2000). As a result of this waterstress avoidance strategy, global photosynthetic productivity may decrease and thus impact the carbon flow to different sink organs.

Most research on the effect of water deficit on sugar metabolism and phloem loading has been led using sucrose-translocating species and demonstrates that in leaves, carbohydrate levels are altered by drought. Sucrose and hexose amounts increase, while starch levels decrease (Pelleschi et al., 1997), suggesting the induction of starch hydrolysis and sucrose synthesis. In cotton, water-stress-induced accumulation of sucrose in the source leaves has been hypothesized as providing an energy supply to maintain cell survival in high-respiration environments (Burke, 2007). Furthermore, sucrose and hexose accumulation is considered to play a major role in osmotic adjustment to maintain metabolic activity in source leaves. However, sugars may also accumulate in leaves because of a decreased demand as a consequence of growth limitation (Hummel et al., 2010).

The effects of water deficit on species that translocate raffinose family oligosaccharides (RFOs) were also investigated since RFOs are involved in desiccation tolerance in seeds (Koster and Leopold, 1988) and in low-temperature acclimation of leaves (Bachmann and Keller, 1995). A hypothetical model depicting the effects of water-deficit stress on the carbon flow between RFOs and $\mathrm{O}$-methyl-inositol (OMI) has been proposed in Coleus, a drought-tolerant plant. Under stress, reduced RFO levels were observed and, conversely, increased OMI synthesis was noted. The two metabolic pathways share myo-inositol, a ubiquitous plant cyclitol, as an intermediate. In Coleus, the activity of galactinol synthase, an enzyme that catalyses the first step of RFO biosynthesis from UDP-galactose, was found down-regulated by water deficit, thus contributing to lower levels of transportable RFOs (Pattanagul and Madore, 1999).

In source leaves, transcript abundance of several genes encoding enzymes involved in gluconeogenesis such as fructosebiphosphate aldolase (Cramer et al., 2007), in the phosphorylation of soluble sugars such as hexokinase (Whittaker etal., 2001), and in RFO biosynthesis such as galactinol synthase (Taji et al., 2002) increased in response to dehydration stress. Transgenic Arabidopsis plants that overexpressed galactinol synthase produced elevated amounts of galactinol and raffinose, which may function as osmoprotectants and contribute to water-deficit stress tolerance (Taji et al., 2002). Such an apparent discrepancy between RFOtransporting plants such as Coleus and sucrose-transporting ones, such as Arabidopsis, may reflect differential responses of distinct species to water stress.

Water deficit induces changes in the concentrations of the main organic nutrients that move inside the sieve tubes, i.e., sugars and amino acids. Analysis of alfalfa phloem sap, collected by stylectomy, indicated a significant increase in sucrose contents and total amino acid concentrations as the leaf water potential decreased from -0.4 to $-2.0 \mathrm{MPa}$. The change in total amino acid concentration was due to larger amounts of Val, Leu, Ile, Glu, Asp, Thr, and especially Pro (Girousse et al., 1996). Similarly, water stress induced increased sucrose and Pro levels in phloem sap collected from cut petioles of Arabidopsis leaves by the EDTA method (Mewis et al., 2012). 
In sink organs, examples of the negative effects of drought on sink growth have been reported in potato tubers, where osmotic stress promoted sucrose biosynthesis instead of starch biosynthesis via the induction of sucrose-phosphate synthase (SPS) and the inhibition of ADP glucose pyrophosphorylase (AGPase; Geigenberger et al., 1997). The degradation of some storage carbohydrates such as starch and fructans in stems has been correlated to starch accumulation in grains (Yang et al., 2004). Likewise, drought led to a fivefold decrease in cytosolic invertase activity in the seeds of Lupinus albus (Pinheiro et al., 2005), together with an increase in the activity of vacuolar and cytosolic invertases in leaves, suggesting that the amounts of sucrose available for transport to the seeds are reduced under drought (Kim et al., 2000; Pinheiro et al., 2001; Trouverie et al., 2004). As a conclusion, several observations bring evidence for negative effects of dehydration on the sink/source ratio that are detrimental to crop production in terms of biomass redistribution (Cuellar-Ortiz et al., 2008).

Data about the involvement of SUTs in drought and salinity tolerance remain limited. Group IV SUTs have been identified as tonoplast-localized SUT/H+ symporters able to regulate sucrose movement from the vacuole to the cytosol. In rice photosynthetic leaves, the SUT OsSUT2 was up-regulated during drought and salinity treatments (Ibraheem et al., 2011). Using PtaSUT4-RNAisuppressed poplars, (Frost et al., 2012) demonstrated the effects of altered sucrose compartmentation on photosynthesis efficiency and accumulation of water-stress-related RFOs in source leaves. The authors suggest that export and long-distance sucrose transport may be at least partly controlled by SUT-mediated sucrose sequestration within the vacuole.

The effects of water deficit have also been studied at different development stages. Drought stress can induce senescence and enhance reserve mobilization (Chandlee, 2001). In other terms, senescence and reserve mobilization are integral components of plant development and basic strategies in stress mitigation (Cowan et al., 2005). Studies using tomato plants over-expressing Arabidopsis hexokinase showed that increased hexokinase levels in plants induced higher sugar contents, which reduced photosynthetic activity and consequently accelerated senescence in leaves (Dai et al., 1999). Sugar levels can influence leaf progress through senescence as direct causal signals, but also as substrates for carbon mobilization and reallocation to allow plants to alleviate the effects of drought stress (Wingler et al., 1998; Rizhsky et al., 2004; Cramer et al., 2007).

In rice, drought-induced leaf senescence promotes allocation of assimilates to developing grains, shortens grain filling, and increases the grain filling rate (Yang et al., 2002). In soybean, water depletion decreases seed size primarily because of a shortening of the filling period rather than an inhibition of the seed growth rate (Westgate et al., 1989). Since seed growth depends on the supply of assimilates from the maternal plant (source activity), as well as on the demand for assimilates within the embryonic tissues (sink activity), both maternal and embryonic factors contribute to the maintenance of seed growth under water deficit. Thus, the latter authors hypothesized that a rapid depletion of sucrose in and around the embryo would point to a source limitation, whereas a reduction in sucrose uptake would imply a sink limitation. Even though severe water deficit completely inhibits photosynthesis and decreases the sucrose concentration in the cotyledon apoplast by approximately $50 \%$, seeds continue to accumulate dry matter at or near the control rate. Reserve carbohydrates are thus mobilized from all source organs (leaves, stems, and pericarp tissue), and this enhances the apoplastic and/or symplastic supply to support seed filling; water-deficient plants display an increased rate of sucrose uptake relative to their well-watered controls (Westgate et al., 1989), consistent with source limitation.

As an example of fruit development, the ripening grape berry represents a well-characterized example of a very strong sugar sink. Grape yield is reduced under drought, while total sugar content in the surviving berries increases (Huglin, 1986). The early development of grape berry appears as the most drought-sensitive stage, but in spite of negative effects on berry growth, drought does not affect sugar accumulation, confirming that sink strength within individual berries is set by sink activity, not by berry size, as reviewed by Agasse etal. (2009). A shift from a symplasticto an apoplastic-unloading pathway has been demonstrated. It occurs at the onset of ripening, and is accompanied by a concomitant increase of the expression and activity of cell-wall invertases, leading to a massive import of hexoses (Zhang et al., 2006).

Altogether these data indicate that sensitivity to water deficit is particularly acute during reproductive development because photo-assimilate allocation to newly established sinks such as flowers, seeds, and fruit, can be compromised by competition with roots under drought stress. In order to apply this knowledge to crop improvement, more detailed understanding of drought sensitivity at that crucial stage for productivity is needed. In that respect, it is no surprise that selection for drought resistance should result in the choice of traits affected by modifications in the sink/source relationship in response to drought, such as the accumulation of biomass in reproductive organs (Schnyder, 1993).

\section{Effects of mineral deficiency}

Plants acquire mineral nutrients for their growth and development through the roots. Plasticity of the root system architecture is therefore a key adaptation feature that allows plants to cope with a changing environment. As pointed out by Hermans et al. (2006), plants generally respond to a shortage in mineral nutrition by allocating more resources to the organs involved in mineral acquisition, and this results in a larger root surface. Therefore any depletion in mineral supply can have dramatic effects on resource allocation in plants. Marschner et al. (1996) proposed that nutrient deficiency can affect photo-assimilate partitioning either directly via phloem loading and transport or indirectly by depressing sink demand.

As a consequence of plant growth reduction or inhibition by mineral deficiency, sugar concentrations increase in plants and in phloem sap (Peuke, 2010). The question remains as to whether the phloem sugar concentration is a stress response and/or a stress signal (Peuke, 2010).

Response to nitrate limitation. Deficiency in nitrogen leads to an accumulation of carbohydrates in leaves and to a higher level of carbon allocated to the root (Figure 2) that increases the root/shoot ratio (Marschner et al., 1996; Scheible et al., 1997; Remans etal., 2006). Scheible etal. (1997) reported that the 


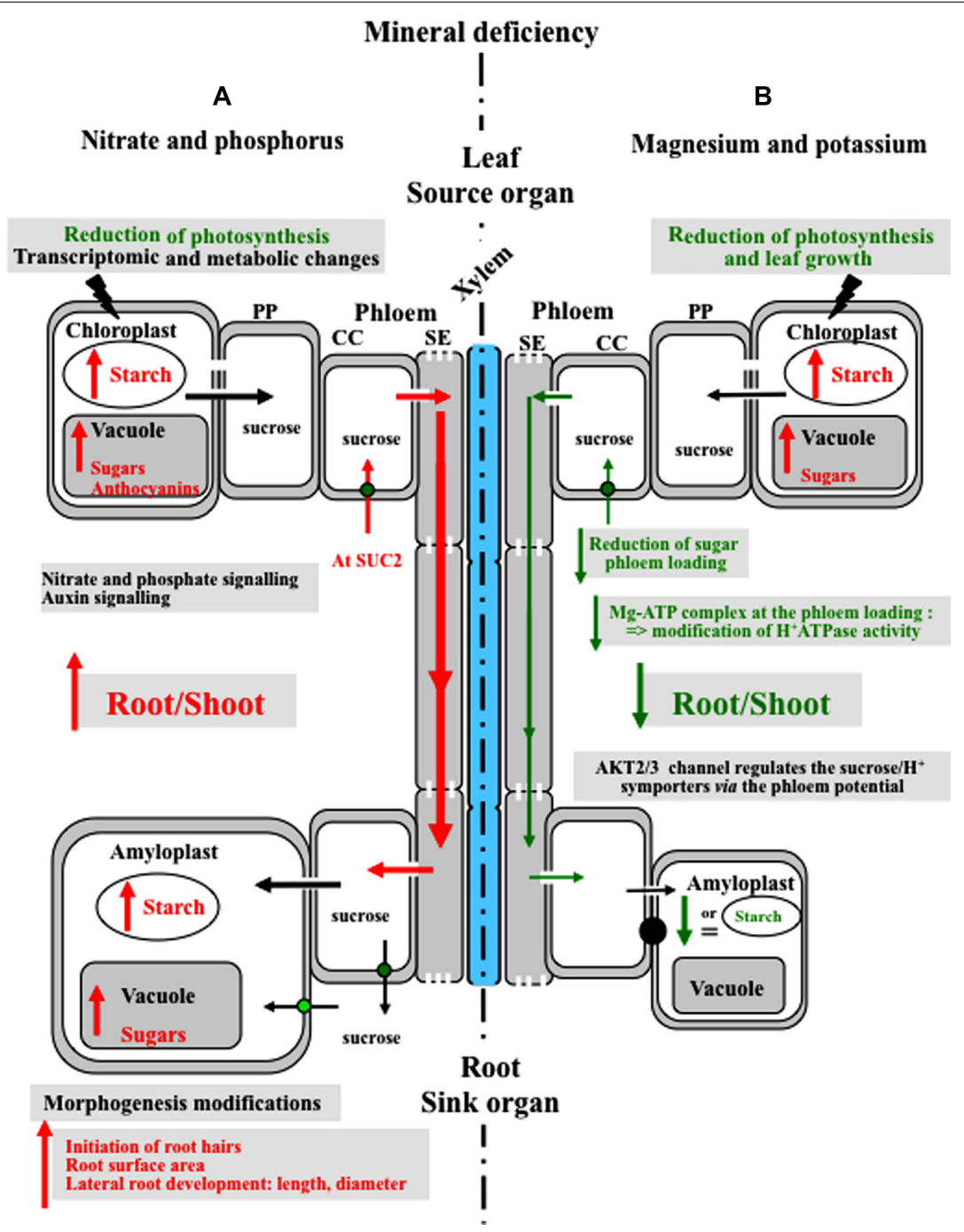

FIGURE 2 | Model of the plant's responses to mineral nutrient deficiency. (A) Response to nitrate and phosphorus deficiency: deficiency in nitrogen and phosphorus leads to reduced photosynthesis, accumulation of sugars in source leaves, increased carbon allocation to the roots and a higher root/shoot ratio. Moreover, phosphorus limitation induces an adaptation of the root system architecture: root hairs initiate and elongate, which increases the root surface area. AtSUC2 (green circle) is a component of the sugar-signaling pathway in the response to phosphorus starvation.

(B) Response to magnesium and potassium deficiency: Mg deficiency increases the concentration of soluble sugars and starch in leaves and reduces leaf growth. Mg deficiency impacts sugar metabolism, as well as sucrose export to the roots. Mg deficiency reduces the Mg-ATP availability and the activity of $\mathrm{H}^{+}$-ATPase, thus reducing the driving force for sucrose phloem loading. AKT2/3 potassium channels affect sugar loading and long-distance transport by regulating the $\mathrm{H}^{+}$/sucrose transporter. Conversely, $\mathrm{K}^{+}$-limitation rarely results in starch accumulation. MC, mesophyll cell; CC, companion cell; PP, parenchyma phloem; MC, mesophyll cell. root growth rate is correlated with the root sugar content, and nitrate accumulation in the shoot acts as a signal to regulate root/shoot allocation in tobacco. Sugars accumulated in the leaves of $\mathrm{N}$-deficient plants lead to reduced photosynthesis probably due to feedback metabolite regulation (Martin et al., 2002; Figure 2). Nitrogen deficiency reduces photosynthesis by a decrease in RubisCO amount and activity and also a decrease in electron transfer (Paul and Driscoll, 1997; Antal et al., 2010). Hermans et al. (2006) gave some clues as to how $\mathrm{N}$ deficiency alters carbohydrate metabolism in the shoot and increases the root/shoot biomass ratio. Arabidopsis microarray data suggest that genes related to primary metabolism and carbohydrate metabolism such as starch metabolism, glycolysis, and disaccharide metabolism are significantly over-represented among the differentially regulated genes in the shoots of N-deficient plants (Hermans et al., 2006). All these data show that nitrogen affects the distribution of sugars across plant organs.

Response to phosphorus limitation. Phosphorus is the second most limiting mineral nutrient for crop production after nitrogen. Lack of phosphorus in leaf mesophyll cells has a direct effect on photosynthesis through Pi availability in the chloroplast and leads to reduced carbon assimilation (Figure 2). Nevertheless, sucrose translocation into the phloem is maintained and 
sometimes increased at least during the early phases of phosphorus starvation (up to 6 days; Hermans et al., 2006).

Like $\mathrm{N}$ deficiency, phosphorus limitation induces increased photo-assimilate allocation to the roots and an adaptation of the root system architecture. Root hairs initiate and elongate in response to phosphate starvation, increasing the root surface area (Hammond and White, 2008).

The importance of phloem sucrose transport in P-deficiency signaling has been clearly demonstrated by Liu et al. (2005). In white lupin roots, two genes responsible for phosphate acquisition (LaPTI, a phosphate transporter and LaSAP1, a secreted acid phosphatase) are rapidly induced by phosphate starvation. When phosphate-starved plants were treated by phloem girdling to prevent shoot-to-root sucrose transport, no induction of either LaPT1 or LaSAP1 was noted. In such conditions, delivery to the roots of ${ }^{14} \mathrm{C}$-sucrose applied onto leaflets was reduced by $95 \%$ in stemgirdled plants. Sucrose transport from shoot to root was therefore necessary for phosphate starvation signaling.

In a search for Arabidopsis plants affected in secreted acid phosphatase activity, Zakhleniuk et al. (2001) identified pho3, a mutant that displays a number of features usually associated with Pi-deficient plants (low Pi, sugar, anthocyanin and starch accumulation in leaves). Moreover, pho3 mutants were unable to respond further to low Pi (Zakhleniuk et al., 2001; Lloyd and Zakhleniuk, 2004). The mutation was subsequently located in the AtSUC2 gene (Lloyd and Zakhleniuk, 2004) and a link was thus clearly established between sucrose availability for long-distance transport and the response to $\mathrm{P}$ starvation. This was confirmed by the overexpression of AtSUC2 in Arabidopsis plants that displayed higher sensitivity to P starvation (Lei et al., 2011; Figure 2). Altogether, these data clearly demonstrate that sucrose transport to the root is a necessary signal for the response to phosphate starvation, although recent data identified miRNAs translocated into the phloem as key players in the regulation of mineral nutrition (Kehr, 2013).

Response to magnesium and potassium deficiency. Metabolic processes and reactions that are influenced by $\mathrm{Mg}$ include chlorophyll formation, photosynthetic carbon dioxide fixation, photoassimilate phloem loading and partitioning (Cakmak and Yazici, 2010). Accumulation of carbohydrates in leaves is a common phenomenon in Mg-deficient plants (Figure 2). Mg deficiency reduces leaf growth more than root growth (Figure 2) and impacts on sucrose export to the roots (Hermans et al., 2004; Hermans et al., 2005; Ding, 2011). Mg deficiency is thought to affect phloem sucrose loading by decreasing Mg-ATP availability. Consequently, $\mathrm{H}^{+}$-ATPase activity could be inhibited, reducing the driving force for active sucrose phloem loading (Marschner et al., 1996; see Figure 1). Moreover, in response to $\mathrm{Mg}$ deficiency, the expression of BvSUT1, a gene encoding a companion cell sucrose $/ \mathrm{H}^{+}$symporter, was induced in the uppermost expanded leaves, but without further enhancement of sucrose loading into the phloem (Hermans et al., 2005).

$\mathrm{K}^{+}$is the major cation in the phloem. Therefore, changes in its amounts can have dramatic effects on phloem functions. The high sugar concentration measured in the leaves of K-deficient plants does not promote any increase in root sugar content or growth. Deeken et al. (2002) demonstrated that AKT2/3 potassium channel affected sugar loading and long-distance transport by regulating sucrose $/ \mathrm{H}^{+}$symporter activity through the pmf (see Figure 1). As a consequence, in the akt2/3 mutants, the amount of sucrose in the phloem sap was drastically reduced. Unlike $\mathrm{N}$ deficiency, $\mathrm{K}^{+}$limitation rarely results in starch accumulation.

In conclusion, enhanced carbohydrate transport to the roots has been demonstrated for $\mathrm{N}$ and $\mathrm{Pi}$ limitation, but not for $\mathrm{K}$ or Mg deficiency (Peuke et al., 1994; Hermans et al., 2006; Figure 2) and the underlying mechanisms have been partly unraveled.

\section{EFFECTS OF NaCl}

Salt stress, due in many places to irrigation with poor quality water, is considered as a major factor limiting plant growth and productivity. Salt stress shares many features with drought stress because in both cases, the primary effect is a lower soil water potential around the roots. Sodium toxicity, due to transport inside the plant via the transpiration stream, adds to that initial stress.

Potassium channels are implied in the recirculation of $\mathrm{Na}^{+}$ inside the plant (Berthomieu et al., 2003). $\mathrm{Na}^{+}$can be loaded into the leaf phloem to be directed to roots for excretion, therefore reducing the amount of $\mathrm{Na}^{+}$in leaves (Berthomieu et al., 2003), although that flux may be marginal compared to the xylem flux (Davenport et al., 2007).

Little is known about the effects of salt stress on sucrose translocation into the phloem. Salt stress has an inhibitory effect on photosynthesis (Suwa et al., 2008) and in many cases it leads to growth impairment, more important in leaves than in roots (Lohaus et al., 2000). In maize, phloem sucrose concentrations were not altered by salt stress, whereas amino-acid and $\mathrm{Na}^{+}$contents of the sieve tube sap increased. The higher amount of amino acids delivered to the roots could partly explain the increased root/shoot ratio (Lohaus et al., 2000). However, in tomato, salt stress can have a direct inhibitory effect on phloem sucrose loading and translocation, leading to a deficit in sucrose partitioning to the roots (Suwa et al., 2008).

Resistance to salt stress is frequently associated with polyolsynthesizing plants as polyols are thought to act both as osmotically active and anti-oxydant molecules. When such plants are subjected to salt stress, their polyol content increases in different organs. Polyols are considered as major molecules for plants to cope with stress (Stoop et al., 1996). In polyol-transporting plants, increased polyol synthesis occurs together with an increased expression of genes encoding polyol transporters located in the phloem in Plantago (Pommerrenig et al., 2007), celery (Landouar-Arsivaud et al., 2011) and olive (Conde et al., 2011), suggesting that longdistance polyol transport is also enhanced in response to salt stress. Increased delivery of polyols to roots could have a positive effect on metabolism and water potential of roots.

\section{EFFECTS OF LIGHT}

Light has a direct effect on phloem loading through photosynthesis via the synthesis of sucrose and by providing energy. However, light also has an effect on the anatomy of the loading zone itself (Amiard etal., 2005, 2007). Depending on the loading mode (apoplastic or symplastic), the response to transfer from low light to high light (and therefore acclimation to increased photosynthesis) was different: in apoplastic species such 
as pea, cell-wall invaginations in the companion cells around the SE increased (Amiard et al., 2005). This indicated an increased exchange surface that allowed for higher sucrose phloem loading. On the contrary, in symplastic loaders such as pumpkin, plasmodesmatal frequencies did not increase, leading to starch accumulation in leaves (Amiard et al., 2005). The capacity of apoplastic loaders to increase the surface for membrane-mediated sucrose transfer around the conducting cells was further investigated (Amiard et al., 2007). Besides its role in nutrient exchange, cell-wall enlargement was proposed as protecting phloem cells against pathogens and insects.

\section{EFFECTS OF LOW TEMPERATURES}

Low temperatures can affect phloem sugar transport in different ways, involving distinct cell types (intermediary cells, parenchyma transfer cells, SEs).Considering that species with a symplastic minor-vein configuration dominate in tropical regions and that species with an apoplastic configuration dominate in temperate zones, temperature is considered as a major parameter of the phloem-loading mode in plants. Symplastic loaders are considered as more cold-sensitive than apoplastic loaders (Gamalei, 1991; Van Bel and Gamalei, 1992). Gamalei et al. (1994) proposed that in herbaceous species and deciduous trees, the collapse of intermediary cells at low temperatures, which leads to decreased photo-assimilate loading, could explain the sensitivity of symplasmic phloem loading to cold. However, these ultrastructural changes have not been observed in broadleaf-evergreen species (Ajuga reptans, Aucuba japonica, and Hedera helix) with a symplastic phloem-loading mode. The winter leaves of these plants have a higher exudation rate at low temperatures and no starch accumulation is observed in their chloroplasts. Therefore, the removal of excessive photo-assimilates from source leaves under low temperature may be necessary to maintain their functional and structural integrity and can thus be regarded as a result of cold acclimation (Hoffmann-Thoma et al., 2001). Later physiological studies (Schrier et al., 2000) revealed no differences between symplastic and apoplastic species in their response to cold. This led to the hypothesis that the phloem-loading mode was related to growth architecture rather than habitat, and was confirmed by a study by Davidson et al. (2011).

In monocot and dicot plant species, tocopherol (vitamin E) deficiency impairs photoassimilate export from source leaves via enhanced callose deposition in the vascular tissues (Hofius et al., 2004). The same effect has also been described for phloem loading under low temperature (Maeda et al., 2006). The Arabidopsis vitamin E2 (vte2) mutants, which lack $\alpha$-tocopherol (the major tocopherol in leaves), exhibit dramatic phenotypes under low temperature. When they are transferred to non-freezing lowtemperatures $\left(+7.5^{\circ} \mathrm{C}\right)$, vte 2 mutants grow more slowly than wild-type plants, and accumulate significantly higher levels of anthocyanins. Accumulation of sucrose and other soluble sugars is much higher in vte2 than in the wild-type after $60 \mathrm{~h}$ of low temperature treatment, although the photosynthesis and carbon fixation rates do not differ between the two genotypes. ${ }^{14} \mathrm{CO}_{2}$-labeling experiments demonstrate that low-temperaturetreated vte 2 plants translocate significantly less ${ }^{14} \mathrm{C}$-labeled photo-assimilates from leaves to roots. In vte 2 mutants, changes in cell structure occur exclusively within the phloem parenchyma "transfer" cells, which exhibit irregular thickenings of cell-wall callose deposits. This process leads to a callose boundary between the phloem parenchyma "transfer" cells and the SE/CC complex. Therefore, tocopherol prevents abnormal callose deposition in phloem parenchyma cell walls and thus maintains photoassimilate transport at low temperature. In Arabidopsis plants acclimated to low temperature $\left(+5^{\circ} \mathrm{C}\right)$, up-regulation of SUTs SUC1 and SUC2 expression represents another mechanism for maintaining sucrose transport to sinks (mainly young leaves; Lundmark et al., 2006).

In dicots, when short sections of stems or petioles are progressively exposed to cool temperatures (thermal jackets), phloem transport stops transiently through the cooled region (Faucher et al., 1982). This stoppage is local and transient as phloem transport can start again even if tissues are maintained at low temperatures (Peuke et al., 2006). Furthermore, the cooling rate determines stoppage duration. In fact, the effect of cooling depends on experimental conditions and SE structure. Conversely, in monocots, i.e., species that lack structural P-proteins (Dinant et al., 2003), assimilate translocation is not (maize) or moderately (wheat) affected by progressive cooling down to $+1^{\circ} \mathrm{C}$ applied to leaves (Faucher and Bonnemain, 1981; Faucher et al., 1982). In maize, limited phloem transport still occurs after a progressive cooling down to $-3^{\circ} \mathrm{C}$, and ${ }^{14} \mathrm{C}$-assimilate allocation in the whole plant remains practically unchanged between $+1^{\circ} \mathrm{C}$ and $+40^{\circ} \mathrm{C}$.

Further studies support the implication of sieve-element structural proteins in the cooling response (Lang and Minchin, 1986). The fact that lanthanum, a calcium channel blocker, can prevent the phloem response to cooling (Pickard and Minchin, 1990), strongly suggests that the response requires an increase in free $\mathrm{Ca}^{2+}$ in the SEs. This increase only occurs if the cooling process is rapid (White, 2009). Recent data indicate that forisomes (a class of P-proteins restricted to Fabacae), which control the immediate $\mathrm{Ca}^{2+}$-dependent occlusion of sieve tubes induced by injuries (Furch et al., 2007; Will et al., 2007), are also involved in the rapid transport blocking by cooling (Thorpe et al., 2010).

\section{EFFECTS OF CO}

The rise in carbon dioxide $\left(\mathrm{CO}_{2}\right)$ in the atmosphere is suspected to be the main cause for global warming. Indeed, atmospheric $\mathrm{CO}_{2}$ concentration increased from around $315 \mathrm{ppm}$ in 1959 to an average 390 ppm nowadays, and predictions give a $\mathrm{CO}_{2}$ concentration ranging between 540 and $970 \mathrm{ppm}$ at the end of the century. This elevated atmospheric $\mathrm{CO}_{2}$ has a direct effect on plant photosynthesis: at the present atmospheric $\mathrm{CO}_{2}$ concentration, the photosynthetic reaction is limited by the low affinity of the active site of RuBisCO for $\mathrm{CO}_{2}$ in $\mathrm{C} 3$ plants (Drake et al., 1997; Woodward, 2002). An increase in $\mathrm{CO}_{2}$ should therefore enhance photosynthetic rates, carbohydrate production, and have a positive effect on phloem transport and growth. In fact, most of the plants grown in high $\mathrm{CO}_{2}$ effectively exhibit increased carbohydrate accumulation in leaves with biomass partitioning between source and sink organs differing according to species (Makino and Mae, 1999). Root/shoot ratios increase in herbaceous plants grown in high $\mathrm{CO}_{2}$ whereas they decrease in trees and remain stable in cereals (Farrar and Williams, 1991). 
Classically, two high- $\mathrm{CO}_{2}$ acclimation steps are described, i.e., short-term and long-term acclimation (Drake et al., 1997; Cheng et al., 1998). Biomass formation is initially enhanced in the first days of exposure but this boosted growth is not sustained for a long time. The short-term response to high $\mathrm{CO}_{2}$ is an acclimation process whereby net photosynthesis, net carbon assimilation and growth are enhanced (Drake et al., 1997; Bae and Sicher, 2004). Excess sucrose is only partly exported to sink organs via the phloem and the resulting carbohydrate accumulation in leaves decreases the photosynthesis rate. A decreased RuBisCO content marks the beginning of long-term acclimation (Cheng et al., 1998; Bae and Sicher, 2004).

A comparison of sugar and starch contents in Ricinus communis leaves in plants grown at 350 or $700 \mathrm{ppm} \mathrm{CO}_{2}$ showed that leaves accumulated starch at $700 \mathrm{ppm}$. Starch accumulated because more sucrose was synthesized than consumed or exported to sink organs via the phloem (Grimmer et al., 1999). Phloem carbon export was induced by high $\mathrm{CO}_{2}$ at night. In the daytime, carbon export was independent of $\mathrm{CO}_{2}$ conditions, whereas at night the export rate dropped by $50 \%$ under normal $\mathrm{CO}_{2}$ but remained unchanged at high $\mathrm{CO}_{2}$. In fact, $R$. communis plants seemed to display sink limitation in the daytime and source limitation at night, and source limitation tended to be suppressed at high $\mathrm{CO}_{2}$ (Grimmer and Komor, 1999). In short, more sucrose was exported to sink organs at high $\mathrm{CO}_{2}$. The role of increased sucrose transport as a result of increased $\mathrm{CO}_{2}$ was also shown in Arabidopsis thaliana grown under $900 \mathrm{ppm} \mathrm{CO}_{2}$ : the plants exhibited enhanced root growth, with increased root length, root diameter and root number, and a modified branching pattern (Lee-Ho et al., 2007). The same root changes were noted on plants grown at $360 \mathrm{ppm} \mathrm{CO}_{2}$ and supplied with exogenous sucrose, confirming the role of sucrose transported from the source.

In Opuntia ficus-indica, a CAM plant, no decrease in photosynthesis was detected in long-term exposure at high $\mathrm{CO}_{2}$. After three months of $\mathrm{CO}_{2}$ enrichment, cladodes displayed an increase in glucose, starch, and malate contents, but no change in their sucrose content was measured (Wang and Nobel, 1996). The sucrose content in mother cladodes was stable because it was exported to daughter cladodes by an enhanced phloem transport that resulted in a $73 \%$ increase in daughter cladode biomass after 3 months of exposure to high $\mathrm{CO}_{2}$ (Wang and Nobel, 1996). However, data analysis from different plant species grown under high $\mathrm{CO}_{2}$ shows that phloem loading cannot alone account for variations in shoot carbohydrate partitioning. Increased $\mathrm{CO}_{2}$ can also have negative effects on plants. Due to an imbalance in nitrate assimilation caused by high $\mathrm{CO}_{2}$, protein accumulation in wheat grains is low despite an unchanged yield (Pleijel and Uddling, 2012). However, this is not the case for woody plants, like pine trees, which preserve seed quality while increasing seed production (Way et al., 2010).

\section{EFFECTS OF SOME SOIL AND AIR POLLUTANTS Effects of cadmium}

Some pollutants like heavy metals, cadmium $(\mathrm{Cd})$, lead $(\mathrm{Pb})$, or mercury $(\mathrm{Hg})$ and the metalloid arsenic (As) are present in soils all over the world. Concerning Cd mobility within the phloem and its impact on sugar transport, little information is available, due to technical hurdles regarding phloem sampling (Mendoza-Cozatl et al., 2011). However, a low-affinity Cd transporter, OsLCT1, involved in phloem loading and accumulation in seeds, was identified in rice (Uraguchi etal., 2011), but no study related to sugar transport was carried out. Another experiment was led on willows used for Cd phyto-extraction. In those trees, sieve tubes and companion cells degenerated in proportion to increasing Cd concentrations supplied at the root level (Vollenweider et al., 2006). Long-distance transport was therefore impaired and a reduction in leaf size and biomass was observed (Cosio et al., 2006). Phloem degeneration was also noticed on maize grown on a Cd-contaminated soil (Cunha et al., 2008). Moreover, in willows, phloem regeneration was hindered due to reduced cambial activity (Vollenweider et al., 2006).

\section{Effects of ozone}

Tropospheric ozone is the most widespread air pollutant in many areas of the industrialized world and the overall ozone concentration has increased over the past decades as a result of anthropogenic activities (Krupa and Manning, 1988; Volz and Kley, 1988). Ozone mainly originates from photochemical reactions of volatile organic compounds with nitrogen oxides (NOx) released from anthropogenic and natural sources (Stockwell et al., 1997). Ozone causes a series of negative effects on vegetation such as decreased photosynthesis and growth, enhanced premature senescence and reduced crop yield (Pell and Dann, 1991; Sandermann, 1996). O $\mathrm{O}_{3}$ alters chloroplast membranes and decreases photosynthesis by reducing RuBisCO activity and concentration (Grams et al., 1999), which suggests that its main target is the photosynthetic apparatus (Kangasjärvi et al., 1994). Thus the availability of photo-assimilates for sink organs is decreased (Fiscus et al., 2005; Grantz et al., 2006).

Grantz and Yang (2000) tried to understand whether the impact of $\mathrm{O}_{3}$ on reduced carbon allocation in plants was due to source limitation or inhibition of translocation. The results indicate that ozone has direct effects on phloem transport with consequent inhibition of translocation to roots, as previously suggested by Mortensen and Engvild (1995). These data are consistent with a primary effect on phloem loading and secondary feedback inhibition of photosynthesis (Grantz, 2003; Grantz et al., 2006).To gain information on this phenomenon, a meta-analysis of all the data available about the impacts of $\mathrm{O}_{3}$ on root/shoot allocation and growth was performed by comparing RGR (relative growth rate of the whole plant) values and the allometric coefficient $k$ $\left(\mathrm{k}=\mathrm{RGR}_{\text {root }} / \mathrm{RGR}_{\text {shoot }}\right)$. The results show that both parameters were significantly reduced by ozone but $\mathrm{k}$ showed more variability than RGR. This could indicate that root allocation is disturbed by $\mathrm{O}_{3}$ but photo-assimilate availability is not. This result is consistent with an inhibition of photo-assimilate translocation rather than with a limitation of the photosynthetic process (Grantz et al., 2006).

Carbon translocation from source leaves of Pima cotton has been directly studied by monitoring ${ }^{14} \mathrm{C}$-labeled photo-assimilates during a sudden exposure to $\mathrm{O}_{3}$. The results indicate that the total labeled carbohydrates transported from source leaves were reduced by $\mathrm{O}_{3}$ through effects on assimilation (up to 20\%) and on export from leaves (up to 70\%; Grantz, 2003; Grantz et al., 2006). Another study examined the translocation velocity of 
${ }^{14}$ C-labeled photo-assimilates in wheat : although the authors observed no significant difference in the translocation velocity in $\mathrm{O}_{3}$-treated plants, the amount of carbon transported decreased (Mortensen and Engvild, 1995). In conclusion, $\mathrm{O}_{3}$ could induce changes in carbon allocation or partitioning probably due to decreased amounts of transported carbon. All those works highlight that the major impact of ozone is the reduction of phloem loading probably linked to oxidant damage on plasmalemma or plamodesmata in mesophyll or phloem companion cells (Grantz and Farrar, 1999).

$\mathrm{O}_{3}$ exposure could also have an indirect effect on plants by blocking phloem translocation via the induction of callose deposition on phloem sieve plates (Wilkinson et al., 2012). In potato, accumulation of callose in the phloem and starch in the parenchyma cells of source leaves was observed after ozone exposure. $\mathrm{O}_{3}$ also decreased tuber weight, supporting the hypothesis of impaired phloem functioning (Asensi-Fabado et al., 2010). A better understanding of the effects of $\mathrm{O}_{3}$ on carbohydrate translocation could come through the study of apoplastic and symplastic phloem-loading species to confirm the oxidant impact of $\mathrm{O}_{3}$ on membranes (Grantz and Yang, 2000).

\section{Effects of sulfur dioxide}

Sulfur dioxide $\left(\mathrm{SO}_{2}\right)$ was a major air pollutant during the second half of the 20th century and was considered as the main cause of forest decline in central Europe (Kurczyńska et al., 1997). $\mathrm{SO}_{2}$ is highly soluble in water: a concentration of $0.035 \mathrm{ppm} \mathrm{SO}_{2}$ in the air can produce up to $35 \mathrm{ppm} \mathrm{SO}_{2}$ in aqueous solution (Puckett et al., 1973). The pollutant can accumulate in leaf tissues and cause disturbances in physiological mechanisms such as photosynthesis, respiration, transpiration (Saxe and Murali, 1989). In bean leaves (Minchin and Gould, 1986) and castor bean cotyledons (LorencPlucinska and Ziegler, 1987), photo-assimilate translocation is also affected due to inhibited phloem loading, independently of reduced photosynthesis. In broad bean, $\mathrm{H}^{+}$/ATPase and SUTs have been identified as possible targets, both in leaf discs (Maurousset et al., 1992b) and plasma membrane vesicles (Maurousset et al., 1992a). More recently, an anatomical study showed that $\mathrm{SO}_{2}$ led to a decreased number of phloem cells, but it was difficult to discriminate between general reduction of cambial activity and disturbances in the division of phloem mother cells (Kurczyńska et al., 1997).

\section{EFFECTS OF BIOTIC STRESS}

During their development, plants have to deal with the presence of microbes, like fungi, viruses, bacteria and also herbivores and sometimes other plants that act as parasites. Those organisms, whatever their type, develop at the expense of the sugars produced by plants (Figure 3), and may therefore affect phloem transport of sugars.

\section{MUTUALISTIC AND PATHOGENIC MICROBES}

Microorganisms can be separated into two groups according to their lifestyles, mutualistic (e.g., mycorrhiza) and pathogenic (biotrophic to necrotrophic; Newton et al., 2010). Even if their modes of colonization are different, microorganisms have evolved sophisticated strategies to avoid, suppress or bypass plant defenses and to divert nutrients, especially sugars, from the host plant for their growth (Figure 3). For example, mutualistic microorganisms and biotrophic pathogens can grow within the plant through complex interfaces, arbuscules and haustoria respectively, through which nutrients are transferred (Voegele and Mendgen, 2011; Smith and Smith, 2012). In contrast, necrotrophic pathogens secrete toxins and produce hydrolytic enzymes that kill host cells in order to feed on macerating tissues (van Kan, 2006).

Microbes can colonize either sink or source organs. Because both mutualistic and pathogenic interactions require sugar supply from host plants to the heterotrophic colonizing agent, they interfere with the source-sink balance. In most cases, it is largely assumed that colonized source organs are subjected to a sourceto-sink transition that modifies the mechanism of sugar transport and partitioning at the whole plant level (Biemelt and Sonnewald, 2006). Among pathosystems, interactions between plants and biotrophic fungi are often cited as models for the study of pathogen-related modifications of carbon partitioning. For this reason, we particularly focus here on plant-biotrophic fungus interactions and only mention a few distinctive features of other pathosystems.

Biotrophic fungi, e.g., rust, powdery mildew, establish a longterm feeding relationship with the living cells of their hosts through the formation of haustoria. These are penetrating cellwall structures that leave the protoplast of host cells intact and create an apoplastic interface through which released host nutrients are absorbed by the fungus (Mendgen and Hahn, 2002; Panstruga, 2003). Autoradiography studies using radiolabeled substances give indirect evidence for the central role of haustoria in sugar and amino-acid transfer from host to biotrophic pathogens (Hall and Williams, 2000; Voegele and Mendgen, 2011). In infected tissues, the fungal carbon demand creates an additional major sink that competes with host sinks. Competitiveness between plant and fungal sinks has been recently examined using a combined experimental-modeling approach. The authors showed that, in wheat infected by the leaf rust fungus Puccinia triticina, fungal sporulation had a competitive priority for photo-assimilates over grain filling (Bancal et al., 2012).

The nature of the host carbon energy source (hexoses or sucrose) transferred through the haustoria has been a matter of debate as to the origin of the apoplastic sugars taken up (Figure 3). Rather than sucrose, glucose appears to be the major carbohydrate imported from the host to the parasite, e.g., powdery mildew (Sutton et al., 1999; Hall and Williams, 2000). Apoplastic sucrose is most likely hydrolysed by cell-wall invertases (cwINV) which are key players in supplying carbohydrates to sink tissues (Roitsch and Gonzalez, 2004). Many studies report increased invertase activity in response to powdery mildew or other pathogens and in different plant species (Roitsch et al., 2003; Kocal et al., 2008; Siemens et al., 2011). This increase in cwINV activity in infected tissues constitutes a major driving force in sugar unloading. For most pathosystems, especially with obligate pathogens, it is difficult to discriminate between plant or pathogen contribution to the induced cwINV activity (Figure 3). While several plant cwINV genes, whose expression is correlated with increased cwINV activity, have been identified (Fotopoulos et al., 2003; Hayes et al., 2010), the pathogen's needs for carbohydrates are unlikely to be 




FIGURE 3 | Simplified representation of the key players involved in the competition for sugars at the plant/microbe interface. Depending on the pathosystem, plants and microbes present efficient machineries to take up or modify apoplastic sucrose. In biotrophic interactions, sucrose can be taken up by both host and fungus via sucrose transporters, e.g., maize ZmSUT1 and fungus Ustilago maydis UmSRT1, respectively. However, glucose is the main carbon source transferred from the host to the parasite and is essential for the feeding and metabolism of the parasite. Cell wall invertases from host and microbes contribute to the source of hexoses at the apoplast level. Hexose transporters allow pathogenic or mutualistic fungi to preferentially compete for glucose and/or fructose (i.e., UfHXT1, BcFRT1, CgHXTs,
GiMST2). To gain access to apoplastic hexoses, plants possess a large repertoire of STPS that can support host demand. Multiple roles of hexoses in host cells have been described; among others, hexoses can be used as an energy source or as signaling molecules and regulators of pathogenesis-related, photosynthetic and sink gene expression. An indirect consequence of host sucrose and hexose acquisition is a possible starvation of microbes through a limited access to sugar at the interface. Host sugar uptake can be bypassed in some pathogenic interactions. Specific effectors (not represented in the diagram) released by some bacteria and probably fungi can manipulate host sugar effluxers (SWEETs) and further make sucrose and hexoses available for the pathogen solely met by the enzymatic machinery of the host. So far few studies have reported fungal cwINV involved in such activities. The characterization of rust fungus Uromyces fabae Uf-INV1 suggests a fungal contribution to the higher cwINV activity in the biotrophic interaction with the host plant Vicia faba (Voegele et al., 2006). Regarding the necrotrophic parasite Botrytis cinerea, a contribution of the fungus to higher cwINV activity during infection of Vitis vinifera has been evidenced (Ruiz and Ruffner, 2002). Accordingly, both partners appear to activate their own invertases, providing strong support to the theory that infection by pathogens creates a new sink that competes with existing sinks (Figure 3). As a consequence, hexoses accumulate in the apoplast, and are taken up by co-regulated hexose transporters (Wright et al., 1995; Clark and Hall, 1998).

High extracellular sugar levels are somehow beneficial for both partners. On the plant side, sugars act as signaling molecules that can regulate many physiological processes, including defense mechanisms through the control of gene expression (Herbers et al., 1996; Roitsch et al., 2003; Rolland et al., 2006; Figure 3). For example, sugars induce pathogenesis-related genes and repress photosynthetic genes (Roitsch, 1999; Bolouri Moghaddam and Van den Ende, 2012). An indirect host defense strategy consists in starving the pathogen by limiting host sugar availability at the interface. Reports describe an increased capacity for glucose retrieval by host tissues after challenge by biotrophic as well as necrotrophic pathogens (Fotopoulos et al., 2003; Azevedo et al., 2006). Some plant monosaccharide transporters (MSTs) are involved in sugar resorption upon infection (Buttner, 2010; Slewinski, 2011). This is exemplified by the report of the up-regulation of the plant cellwall invertase At $\beta$ FRUCT1 and the hexose transporter AtSTP4 in Erysiphe cichoracearum-infected Arabidopsis leaves, which correlates with increased invertase activity and glucose resorption 
(Truernit et al., 1996; Fotopoulos et al., 2003). This supports the functional coordination of STPs and cwINVs in the supply of sink tissues with hexoses (Sutton et al., 2007; Figure 3). Further molecular evidence of a competition for apoplastic glucose has been provided in infected broad bean by the identification and characterization of rust Uromyces fabae sugar transporter UfHXT1, which is localized in the haustorial plasma membrane. UfHXT1 preferentially transports glucose and fructose rather than sucrose to the fungus (Voegele et al., 2001). Substrate specificity and localization of such fungal MSTs facilitates plant hexose assimilation and thus participates in fungal sink strength (Figure 3).

Mutualistic or pathogenic microorganisms use a wide range of different strategies to gain access to carbohydrates from host plants, as highlighted in Figure 3. Mycorrhizal fungus Glomus high-affinity MST2 has been identified as a major player in sugar uptake with a critical function in the establishment of symbiosis (Helber et al., 2011; Doidy et al., 2012). Five hexose transporters (CgHXT1-5) have been characterized in the maize hemibiotrophic pathogen Colletotrichum graminicola, with large substrate specificities. CgHXT genes are differentially expressed during all infection phases, whether biotrophic or necrotrophic (Lingner et al., 2011). A high-affinity fructose transporter (BcFRT1) has been found in the necrotrophic fungus $B$. cinerea. Roles for fructose as a potent inducer of fungus germination have been suggested (Doehlemann et al., 2005).

Sucrose is the main photo-assimilate translocated from source to sinks. Upon release from the phloem in sink organs, sucrose is unloaded into the apoplast and is potentially exploitable by the fungus. In infected tissues, apoplastic sucrose uptake by fungal cells is believed to require the presence of fungal SUTs localized in the haustorial structure. The identification of SRT1, a highly specific SUT from the corn smut fungus Ustilago maydis, suggests that this fungus can efficiently use apoplastic sucrose (Talbot, 2010; Wahl et al., 2010). Ustilago maydis hyphae grow along the phloem of infected maize plants where they have access to sucrose released from the phloem. Such a transporter (i.e., SRT1) allows the pathogen to compete for sucrose with sink cell sucrose transporters (SUC/SUT) at the plant/fungus interface (Wahl et al., 2010; Doidy et al., 2012). During the maize/Ustilago maydis interaction, competition for extracellular sucrose between the SUTs ZmSUT1 and UmSRT1 has been described, and SRT1 turned out to be essential for fungal virulence (Wippel et al., 2010). Direct sucrose uptake is probably an integral part of the pathogen's strategy to prevent plant defense responses being triggered by hexoses (mostly glucose) released from sucrose hydrolysis (Ehness et al., 1997). The identification and characterization of other fungal SUTs is not yet achieved and constitutes an open field to better understand the competition for sugars that takes place between the plant and the fungus (Doidy et al., 2012).

Recently, key insights into how microbes acquire the ability to use the host sugar efflux machinery for nutrient supply have been gained thanks to the discovery of a new class of plasma membranelocalized sugar transporters (Figure 3). Plant SWEETs function as facilitators of sugar influx and efflux. SWEETs were at first identified as glucose uniporters but paralogues (i.e., AtSWEET11 and AtSWEET12) can also export sucrose (Chen et al., 2010, 2012). Several SWEET genes are specifically regulated upon pathogen attack. Different patterns of expression have been reported after challenge by either bacterial (Pseudomonas syringae pv tomato strains) or fungal (the necrotroph $B$. cinerea or the biotroph Golovinomyces cichoracearum) pathogens. Authors also described a model in which OsSWEET11 and 14 expression is specifically targeted by Xanthomonas oryzae pv oryzae effectors to increase sugar efflux into the apoplast (Chen et al., 2010). Both specific bacterial effectors and OsSWEET expression are required for bacterial virulence, suggesting that pathogens probably take advantage of the SWEET-induced sugar efflux mechanism to gain access to sugars in cells around the infection site in order to support their own growth. The identification of this non-conventional family of sugar transporters highlights additional complexity and opens new perspectives onto our knowledge about sugar partitioning during plant-pathogen interactions.

\section{VIRUSES}

Among plant pathogens, viruses are unique because they remain exclusively in the symplast of their host (Schoelz et al., 2011). This mode of colonization requires viruses to move from infection site to systemic tissues via the symplastic continuity created by cell-to-cell connections (plasmodesmata, PD) and the phloem long-distance translocation system (Lucas and Wolf, 1999; Gosalvez-Bernal et al., 2008). Viral infection involves virusencoded movement proteins (MPs) which alter the exclusion size of PDs, suggesting that viruses can exploit the PD-mediated cellto-cell trafficking of photo-assimilates. Carbohydrate allocation and signaling can be directly affected during virus infection. The mechanisms of these metabolic changes caused by viral infection have been assessed using transgenic expression of viral MPs; Olesinski et al., 1996; Hofius et al., 2001). Plants expressing viral MPs exhibited dilated PDs associated with significant physiological alterations such as changes in host primary metabolism, accumulation of starch and soluble sugars, decreased photosynthesis and increased respiration (Tecsi et al., 1996; Balachandran et al., 1997; Herbers et al., 2000). These changes strongly suggest that virusinfected leaves function as sinks. However, the effects of viral MPs on carbohydrate allocation can vary according to the way viruses exploit the host transport system. In some cases, it is not related to the PD size exclusion limit, but may rather be due to induced callose deposition at the PD level which consequently blocks symplastic sucrose transport (Biemelt and Sonnewald, 2006).

Virus-induced reallocation of host resources and its mechanisms seem to be virus-specific and result from interactions between specific viral and host components (Culver and Padmanabhan, 2007). For example, in Cucumber Mosaic Virus (CMV)-infected melon, modifications in phloem sap sugar composition, such as an increase in sucrose content, have been reported (Shalitin and Wolf, 2000). While cucurbits are known to be symplastic loaders, the identification of a SUT, CmSUT1, which catalyzes the active apoplastic loading of sucrose into the phloem of CMV-infected melon, provides evidence for a possible symplast/apoplast switch in sucrose loading (Gil et al., 2011).

\section{APHIDS}

Aphids, which are the vectors of numerous plant viruses (Brault et al., 2010; Dedryver et al., 2010), are "experts" at probing the 
phloem and at manipulating the plant tissues to their own advantage (Miles, 1999; Will et al., 2007). Using fine stylets, they drill into tissues intercellularly, making tiny punctures, and wait a few seconds to analyze the physicochemical properties of the microenvironment around the stylet tip (Tjallingii, 2006). Experiments using artificial systems indicate that the ability of aphids to find sieve tubes is linked to their ability to sense high sucrose concentrations and $\mathrm{pH}$ (Hewer et al., 2010).

Aphids constitute an additional sink that can modify assimilate allocation at the whole plant level, especially at the expense of the stem apex (Hawkins et al., 1987; Girousse et al., 2003). Data from various controlled infestations of alfalfa stems by pea aphids indicate that the reduction of the stem elongation rate (SER) is only partly explained by assimilate withdrawal and suggests that extra signals associated to pea aphid probing and feeding are involved in SER reduction (Girousse et al., 2003). In addition, dramatic changes in carbon and nitrogen allocation were observed under growth-chamber conditions using severe and short-time aphid infestations. They mainly consist in nitrogen mobilization from some parts of the stem, especially the apex, to the middle part of the zone of aphid infestation (Girousse et al., 2005). Complementary approaches show that aphid colonization induces changes in the expression of genes associated with sugar and nitrogen metabolism (Voelckel et al., 2004; Divol et al., 2005; de Vos et al., 2007) and causes an increase in the mRNA levels of a MST in infested tissues (Moran and Thompson, 2001). The systemic impact of aphid infestation also concerns source tissues (Miles, 1989). For instance, a single Aphis fabae on one side of a leaf grows faster if an Aphis fabae colony is feeding on the other side (Dixon and Wratten, 1971), suggesting the importance of aphid-related sugar accumulation. Aphid (Myzus persicae) infestation of Arabidopsis leaves leads to a dramatic increase in sucrose and starch contents in source tissues despite pest feeding (Singh et al., 2011). These changes suggest a stoppage of sugar export to the plant sinks. Infestation also induces an increase in trehalose levels. This change in trehalose metabolism promotes re-allocation of carbon into starch at the expense of sucrose, the primary energy source of the pest, and plant defenses via the induction of the PHYTOALEXINDEFICIENT4 gene (Singh et al., 2011). It is noteworthy that the trehalose found in the aphid hemolymph at millimolar concentrations as an energy source is also a plant signal that contributes to controlling infestation by phloem-sucking pests such as $M$. persicae at micromolar concentrations.

\section{PARASITIC PLANTS}

Many plants like Phelipanche (Orobanche), Cuscuta, and Striga are able to establish parasitic relationships with a large number of crop plants, and this results in important productivity losses. Fighting against these parasitic plants is particularly complex because many treatments are also active on the host plants. Parasitic plants can be classified into two categories: hemiparasites are green, contain chlorophyll and can therefore have a photosynthetic activity. They take nutrients from the xylem sap in the wood of their host, can reduce nitrate but also use organic nitrogen found in the sap of their host. Holoparasitic plants are not photosynthetic and are thus heterotrophic for carbon and depend on their host for sugars, water, and minerals (Abbes etal., 2009a). Parasitic plants establish their connections with the host at the level of the sap-conducting tissues. Several years ago, sugar trafficking between host plant and parasite was clearly demonstrated using radiolabelled molecules. Although it is altogether agreed that the transfer of water and minerals between host and parasite xylem vessels does not require a membrane, the connections between host and parasite phloem vessels are more disputed. Initial histological studies showed that plasmodesmata were absent (Behnke et al., 1990), suggesting an apoplastic transfer of sugars and other molecules (Wolswinkel, 1974; Jeschke et al., 1994). However, using a GFP specifically expressed in companion cells (Haupt et al., 2001) or a fusion GFP-TMV (Tobacco Mosaic Virus) MP (Birschwilks et al., 2006), secondarily formed interspecific plasmodesmata were shown to be open and functional. In addition, ${ }^{3} \mathrm{H}$-sucrose, 5,6carboxyfluorescein and viruses were translocated from the host to the parasite, giving unequivocal evidence for a symplastic transfer of solutes (Hibberd and Jeschke, 2001; Birschwilks et al., 2006).

Different enzyme activities are involved in the parasitic mechanism. PrSUS1, a sucrose synthase isolated from the parasitic plant Phelipanche ramosa, exhibits a spatial and temporal regulation during the infection process (Péron et al., 2012). Expression is regulated by auxin from the host plant. The authors suggest that PrSUS1 is involved in cellulose synthesis during the secondary thickening of differentiating xylem elements in the tubercles (i.e., globular structures developed after parasite seed germination that carry numerous adventitious roots and whose apical bud produces a subterranean shoot) and in the adventitious roots of $P$. ramosa. Cellulose synthesis is probably crucial for the cell-wall integrity of both xylem and phloem tissues. Another enzyme activity acting as the driving force in many source/sink relationships is the invertase activity involved in the cleavage of sucrose into glucose and fructose. Transcripts of PrSail that encodes a soluble acid invertase and the corresponding enzyme activity were high in growing organs during parasite fixation. In addition, germinated seeds displayed enhanced cell-wall invertase activity (PrCWI), suggesting its contribution to the sink strength of infected roots during the subsequent step of root penetration (Draie et al., 2011).

Orobanche also accumulates high amounts of polyols like mannitol, and this decreases the osmotic potential below that of the host plant (Harloff and Wegmann, 1993; Abbes et al., 2009b). This mechanism is essential for increasing the parasite's sink strength. A mannose-6-phosphate reductase (M6PR), the key enzyme of the mannitol biosynthesis pathway, was identified and cloned from Orobanche (Delavault et al., 2002). Expression of that gene was induced at the attachment stage and sucrose from the phloem host was rapidly converted into mannitol. Consequences are increases in host nutrient uptake and in parasite protein synthesis and vegetative growth. Accumulation of mannitol in Orobanche tissues is strongly enhanced following the haustorial connection. Targeting the corresponding enzyme activity could be a major strategy for fighting against these parasites (Delavault et al., 2002).

All these relationships in terms of carbon and nitrogen exchanges are very important to establish susceptibility or tolerance to Orobanche. Phloem exudates of a faba bean tolerant line were highly deficient in nitrogen compared to those of the susceptible line (Abbes et al., 2009a). In addition, after haustorial development and phloem connections were established 
with the tolerant line, soluble invertase activity was very low. Taken together, these results indicate that the reduced growth of Orobanche on the tolerant faba bean line resulted from a reduced capacity to use the host-derived carbohydrates and lower sink strength.

Using radiolabelled valine and asparagine, amino acids were also shown to be transported from the host to Cuscuta europaea (Wolswinkel et al., 1984). More recently, Aly et al. (2011) demonstrated that several other molecules such as proteins and macromolecules could be translocated to Phelipanche aegyptiaca through phloem connections. These results suggest that targeting the delivery of proteins and/or nucleic acids could be very interesting in the development of parasite-resistant strategies. The use of herbicides could also be a strategy to get rid of parasitic plants. Glyphosate, a systemic herbicide, is accumulated in the parasite due to its strong sink activity, without significant damage to the host (Nadler-Hassar et al., 2004). Glyphosate usually inhibits 5-enolpyruvylshikimate-3-phosphate synthase (EPSPS), a key enzyme in the shikimate pathway. However, in parasitic plants, glyphosate also blocks the transfer of sugars and macromolecules to the parasite. Therefore its toxic effect is more due to the inhibition of phloem transport to the parasite than to the inhibition of aromatic amino acid synthesis.

\section{CONCLUSION AND PERSPECTIVES}

Plant life cycle is characterized by source-sink transitions due to changes in sink strength or in the number of sink organs competing for a common pool of sugars (Roitsch, 1999). The phloem plays a major role in connecting source and sink organs and supplying sugars, mainly in the form of sucrose, to sinks. As demonstrated in this review, phloem transport of sugar is tightly regulated and is very sensitive to alterations in a plant's environment resulting in changes in carbon allocation to sinks. However, there are few reports on the effects of biotic and abiotic factors on phloem transport and dealing with all components from source to sink.

At the source level, sucrose availability for export is dependent on photosynthetic activity. Interestingly, in many cases of adverse environmental conditions when photosynthetic carbon fixation was reduced, photosynthesis was not the primary target of the stress. Phloem transport of sugars was also affected, earlier than photosynthesis, leading to an increase of sucrose concentration in leaves and a feed-back inhibition of photosynthesis and sucrose export (Ainsworth and Bush, 2011).

Recent works have pointed out sucrose concentrations in the cytosol of mesophyll cells as a key factor for the regulation of sucrose export. The characterization of tonoplastic hexose and SUTs provides new support for the role of transient sugar storage in the vacuole to control the cytoplasmic sucrose concentration (Wingenter et al., 2010).

One interesting conclusion is that the structure of phloem cells can be altered by several abiotic stresses (light, $\mathrm{SO}_{2}, \mathrm{O}_{3}$ ). As the ultra-structure and integrity of such cells are poorly investigated, these alterations may be more frequent than reported. Additional evidence for the plasticity of phloem companion or parenchyma cell-wall comes from several studies on the effect of light (Amiard et al., 2005, 2007). Structural changes in the cell-wall and invaginations of the plasma membrane can increase fluxes of assimilates in the case of high light. Conversely, there are several reports of callose synthesis at different levels in the SEs, in response to external biotic or abiotic stresses. This physical constraint leads also to impaired transport of sucrose to sinks.

At the sink level, environmental cues can alter priority between different sinks: for example, increase in the root to shoot ratio is induced by mineral deficiency and both sucrose and ions are signals between root and shoot. Stress-related increase in sucrose or polyol delivery to sinks (e.g; roots but also seeds) is important for sink growth, cell turgor, and water potential maintenance.

Little is known about the regulation of sugar transporters during abiotic stress at the molecular level despite their important role in the allocation of sugars in plants. This knowledge gap is due to the fact that many studies were conducted at a physiological level. Understanding the changes in transporter expression during stress is therefore a major challenge in order to predict and act on plant responses. Interesting clues on possible regulation by environmental and biotic factors were obtained by searching for putative regulatory elements in the promoters of sugar transporters in grape and Arabidopsis (Afoufa-Bastien et al., 2010). Recent data on biotic stress have unraveled the pathways of sugar exchange, and the corresponding molecular players have been identified (Doidy et al., 2012). Unexpectedly, sucrose can be absorbed by both host and pathogen, while it is commonly admitted that glucose resulting from the invertase activity is the main host sugar taken up by pathogens. These new findings highlight the complexity of sugar exchanges at the host/pathogen interface.

In order to understand further the distribution of carbon between sinks, future studies need to concentrate on the measurement of the phloem sap flux in relation with the expression of sugar transporters, taking advantage of new imaging techniques (Knoblauch and Oparka, 2012) combined with traditional ${ }^{14} \mathrm{CO}_{2}$ labeling. Key information should be obtained from metabolomic approaches of phloem sap composition (Fiehn, 2003). As pointed out earlier in this review and by Ainsworth and Bush (2011), there are interesting possibilities for increasing source activity and sink demand by manipulating the expression of selected transporter genes (Schroeder et al., 2013).

Concerning the acclimation of plants to some major environmental adverse conditions (drought and salt stress, pathogens), several sugars transported on long-distances such as polyols can also be targeted for improving stress resistance (Merchant and Richter, 2011). Nevertheless, the role of other sugars such as trehalose as signaling molecules will have to be taken into account. There are still considerable efforts to be made before getting a clear understanding of the role of phloem transport on source-sink relationships under stress conditions, but any progress should have beneficial effects on crop production.

\section{ACKNOWLEDGMENTS}

The authors wish to thank Sylvie Clercy-Morel for invaluable help in editing the manuscript and the corresponding literature. PL and MD are funded by a grant from the French ministry of research and higher education and Jonathan Parrilla by a grant from the Région Poitou-Charentes. 


\section{REFERENCES}

Abbes, Z., Kharrat, M., Delavault, P., Chaïbi, W., and Simier, P. (2009a). Nitrogen and carbon relationships between the parasitic weed Orobanche foetida and susceptible and tolerant faba bean lines. Plant Physiol. Biochem. 47, 153-159.

Abbes, Z., Kharrat, M., Delavault, P., Chaïbi, W., and Simier, P. (2009b). Osmoregulation and nutritional relationships between Orobanche foetida and faba bean. Plant Signal. Behav. 4, 336-338.

Afoufa-Bastien, D., Medici, A., Jeauffre, J., Coutos-Thevenot, P., Lemoine, R., Atanassova, R., et al. (2010). The Vitis vinifera sugar transporter gene family: phylogenetic overview and macroarray expression profiling. BMC Plant Biol. 10:245. doi: 10.1186/1471-2229-10-245

Agasse, A., Vignault, C., Kappel, C., Conde, C., Gerós, H., and Delrot, S. (2009). "Sugar transport and sugar sensing in grape," in Grapevine Molecular Physiology and Biotechnol$o g y$, ed. K.A. Roubelakis-Angelakis (Netherland: Springer), 105-139.

Ainsworth, E. A., and Bush, D. R. (2011). Carbohydrate export from the leaf: a highly regulated process and target to enhance photosynthesis and productivity. Plant Physiol. 155, 64-69. doi: 10.1104/pp.110.167684

Aly, R., Hamamouch, N., Abu-Nassar, J., Wolf, S., Joel, D., Eizenberg, H., et al. (2011). Movement of protein and macromolecules between host plants and the parasitic weed Phelipanche aegyptiaca Pers. Plant Cell Rep. 30, 2233-2241. doi: 10.1007/s00299011-1128-5

Amiard, V., Demmig-Adams, B., Mueh, K. E., Turgeon, R., Combs, A. F., and Adams, W. W. III. (2007). Role of light and jasmonic acid signaling in regulating foliar phloem cell wall ingrowth development. New Phytol. 173, 722-731. doi: 10.1111/j.14698137.2006.01954.x

Amiard, V., Mueh, K. E., DemmigAdams, B., Ebbert, V., Turgeon, R., and Adams, W. W. III. (2005). Anatomical and photosynthetic acclimation to the light environment in species with differing mechanisms of phloem loading. Proc. Natl. Acad. Sci. U.S.A. 102, 12968-12973. doi: 10.1073/pnas.0503784102

Antal, T., Mattila, H., Hakala-Yatkin, M., Tyystjärvi, T., and Tyystjärvi, E. (2010). Acclimation of photosynthesis to nitrogen deficiency in Phaseolus vulgaris. Planta 232, 887-898. doi: 10.1007/s00425-010-1227-5

Asensi-Fabado, A., Garcia-Breijo, F. J., and Reig-Arminana, J. (2010).
Ozone-induced reductions in belowground biomass: an anatomical approach in potato. Plant Cell Environ. 33, 1070-1083. doi: 10.1111/ j.1365-3040.2010.02128.x

Azevedo, H., Conde, C., Geros, H., and Tavares, R. M. (2006). The non-host pathogen Botrytis cinerea enhances glucose transport in Pinus pinaster suspension-cultured cells. Plant Cell Physiol. 47, 290-298. doi: $10.1093 / \mathrm{pcp} /$ pci248

Bachmann, M., and Keller, F. (1995). Metabolism of the raffinose family oligosaccharides in leaves of Ajuga reptans L. (inter- and intracellular compartmentation). Plant Physiol. 109, 991-998. doi: 10.1104/ pp.109.3.991

Bae, H., and Sicher, R. (2004). Changes of soluble protein expression and leaf metabolite levels in Arabidopsis thaliana grown in elevated atmospheric carbon dioxide. Field Crop. Res. 90, 61-73. doi: 10.1016/j.fcr.2004.07.005

Balachandran, S., Hurry, V. M., Kelley, S. E., Osmond, C. B., Robinson, S. A., Rohozinski, J., et al. (1997). Concepts of plant biotic stress. Some insight into the stress physiology of virusinfected plants, from the perspective of photosynthesis. Physiol. Plant. 100, 203-213. doi: 10.1111/j.13993054.1997.tb04776.x

Bancal, M.-O., Hansart, A., Sache, I., and Bancal, P. (2012). Modelling fungal sink competitiveness with grains for assimilates in wheat infected by a biotrophic pathogen. Ann. Bot. 110, 113-123. doi: 10.1093/aob/mcs094

Behnke, H. D., Sjolund, R. D., and Dörr, I. (1990). "Sieve elements in haustoria of parasitic angiosperms," in Sieve Elements. Berlin: Springer, 239-256.

Berthomieu, P., Conejero, G., Nublat, A., Brackenbury, W. J., Lambert, C., Savio, C., et al. (2003). Functional analysis of AtHKT1 in Arabidopsis shows that $\mathrm{Na}(+)$ recirculation by the phloem is crucial for salt tolerance. EMBO J. 22, 2004-2014. doi: 10.1093/emboj/cdg207

Biemelt, S., and Sonnewald, U. (2006). Plant-microbe interactions to probe regulation of plant carbon metabolism. J. Plant Physiol. 163, 307-318. doi: 10.1016/ j.jplph.2005.10.011

Birschwilks, M., Haupt, S., Hofius, D., and Neumann, S. (2006). Transfer of phloem-mobile substances from the host plants to the holoparasite Cuscuta sp. J. Exp. Bot. 57, 911-921. doi: 10.1093/jxb/erj076

Bolouri Moghaddam, M. R., and Van den Ende, W. (2012). Sugars and plant innate immunity. J. Exp. Bot.
63, 3989-3998. doi: 10.1093/jxb/ ers129

Brault, V., Uzest, M., Monsion, B., Jacquot, E., and Blanc, S. (2010). Aphids as transport devices for plant viruses. CR Biol. 333, 524-538. doi: 10.1016/j.crvi.2010.04.001

Burke, J. J. (2007). Evaluation of source leaf responses to water-deficit stresses in cotton using a novel stress bioassay. Plant Physiol. 143, 108-121. doi: 10.1104/pp.106.087783

Buttner, M. (2010). The Arabidopsis sugar transporter (AtSTP) family: an update. Plant Biol. 12(Suppl. 1), 35-41. doi: 10.1111/j.14388677.2010.00383.x

Cakmak, I., and Yazici, M. (2010). Magnesium: a forgotten element in crop production. Better Crops 94 23-25.

Carpaneto, A., Geiger, D., Bamberg, E., Sauer, N., Fromm, J., and Hedrich, R. (2005). Phloem-localized, protoncoupled sucrose carrier ZmSUT1 mediates sucrose efflux under the control of the sucrose gradient and the proton motive force. J. Biol. Chem. 280, 21437-21443. doi: 10.1074/jbc.M501785200

Chandlee, J. M. (2001). Current molecular understanding of the genetically programmed process of leaf senescence. Physiol. Plant. 113, 1-8. doi: 10.1034/j.1399-3054.2001.1130101.x

Chen, L. Q., Hou, B. H., Lalonde, S., Takanaga, H., Hartung, M. L., Qu, X. Q., etal. (2010). Sugar transporters for intercellular exchange and nutrition of pathogens. Nature 468 527-532. doi: 10.1038/nature09606

Chen, L. Q., Qu, X. Q., Hou, B. H., Sosso, D., Osorio, S., Fernie, A. R. et al. (2012). Sucrose efflux mediated by SWEET proteins as a key step for phloem transport. Science 335, 207 211. doi: $10.1126 /$ science. 1213351

Cheng, S.-H., Moore, B. D., and Seemann, J. R. (1998). Effects of short- and long-term elevated $\mathrm{CO} 2$ on the expression of ribulose-1,5bisphosphate carboxylase/oxygenase genes and carbohydrate accumulation in leaves of Arabidopsis thaliana (L.) heynh. Plant Physiol. 116, 715723. doi: 10.1104/pp.116.2.715

Chiou, T.-J., and Bush, D. R. (1998). Sucrose is a signal molecule in assimilate partitioning. Proc. Natl. Acad. Sci. U.S.A. 95, 4784-4788. doi: 10.1073/pnas.95.8.4784

Clark, J. I. M., and Hall, J. L. (1998). Solute transport into healthy and powdery mildew-infected leaves of pea and uptake by powdery mildew mycelium. New Phytol. 140, 261-269. doi: 10.1046/j.1469-8137. 1998.00263.x
Conde, A., Silva, P., Agasse, A., Conde, C., and Geros, H. (2011). Mannitol transport and mannitol dehydrogenase activities are coordinated in Olea europaea under salt and osmotic stresses. Plant Cell Physiol. 52, 17661775. doi: $10.1093 / \mathrm{pcp} / \mathrm{pcr} 121$

Cosio, C., Vollenweider, P., and Keller, C. (2006). Localization and effects of cadmium in leaves of a cadmium-tolerant willow (Salix viminalis L.). Environ. Exp. Bot. 58, 6474. doi: 10.1016/j.envexpbot.2005. 06.017

Courtois, B., Mclaren, G., Sinha, P. K., Prasad, K., Yadav, R., and Shen, L. (2000). Mapping QTLs associated with drought avoidance in upland rice. Mol. Breed. 6, 55-66. doi: 10.1023/A:1009652326121

Cowan, A. K., Freeman, M., Bjorkman, P. O., Nicander, B., Sitbon, F., and Tillberg, E. (2005). Effects of senescence-induced alteration in cytokinin metabolism on source-sink relationships and ontogenic and stress-induced transitions in tobacco. Planta 221, 801-814. doi: 10.1007/s00425-005-1489-5

Cramer, G. R., Ergul, A., Grimplet, J., Tillett, R. L., Tattersall, E. A., Bohlman, M. C., et al. (2007). Water and salinity stress in grapevines: early and late changes in transcript and metabolite profiles. Funct. Integr. Genomics 7, 111-134. doi: 10.1007/s10142-006-0039-y

Cuellar-Ortiz, S. M., De La Paz ArrietaMontiel, M., Acosta-Gallegos, J., and Covarrubias, A. A. (2008). Relationship between carbohydrate partitioning and drought resistance in common bean. Plant Cell Environ. 31, 1399-1409. doi: 10.1111/j.13653040.2008.01853.x

Culver, J. N., and Padmanabhan, M. S. (2007). Virus-induced disease: altering host physiology one interaction at a time. Annu. Rev. Phytopathol. 45, 221-243. doi: 10.1146/ annurev.phyto.45.062806.094422

Cunha, K. P., Do Nascimento, C. W., Pimentel, R. M., and Ferreira, C. P. (2008). Cellular localization of cadmium and structural changes in maize plants grown on a cadmium contaminated soil with and without liming. J. Hazard. Mater. 160, 228-234. doi: 10.1016/ j.jhazmat.2008.02.118

Dai, N., Schaffer, A., Petreikov, M., Shahak, Y., Giller, Y., Ratner, K., et al. (1999). Overexpression of Arabidopsis hexokinase in tomato plants inhibits growth, reduces photosynthesis, and induces rapid senescence. Plant Cell 11, 1253-1266. doi: 10.1105/tpc.11.7.1253 
Davenport, R. J., Munoz-Mayor, A., Jha, D., Essah, P. A., Rus, A., and Tester, M. (2007). The $\mathrm{Na}(+$ transporter AtHKT1;1 controls retrieval of $\mathrm{Na}$ (+ from the xylem in Arabidopsis. Plant Cell Environ. 30, 497507. doi: 10.1111/j.1365-3040.2007. 01637.x

Davidson, A., Keller, F., and Turgeon, R. (2011). Phloem loading, plant growth form, and climate. Protoplasma 248, 153-163. doi: 10.1007/s00709-010-0240-7

de Vos, M., Kim, J. H., and Jander, G. (2007). Biochemistry and molecular biology of Arabidopsis-aphid interactions. Bioessays 29, 871-883. doi: 10.1002/bies.20624

Dedryver, C. A., Le Ralec, A., and Fabre, F. (2010). The conflicting relationships between aphids and men: a review of aphid damage and control strategies. CR Biol. 333, 539-553. doi: 10.1016/j.crvi.2010.03.009

Deeken, R., Geiger, D., Fromm, J., Koroleva, O., Ache, P., LangenfeldHeyser, R., et al. (2002). Loss of the AKT2/3 potassium channel affects sugar loading into the phloem of Arabidopsis. Planta 216, 334-344. doi: 10.1007/s00425-002-0895-1

Delavault, P., Simier, P., Thoiron, S., Véronési, C., Fer, A., and Thalouarn, P. (2002). Isolation of mannose 6phosphate reductase cDNA, changes in enzyme activity and mannitol content in broomrape (Orobanche ramosa) parasitic on tomato roots. Physiol. Plant. 115, 48-55. doi: 10.1034/j.1399-3054.2002.1150105.x

Dinant, S., Clark, A. M., Zhu, Y., Vilaine, F., Palauqui, J. C., Kusiak, C., et al. (2003). Diversity of the superfamily of phloem lectins (phloem protein 2) in angiosperms. Plant Physiol. 131, 114-128. doi: 10.1104/pp.013086

Ding, Y. (2011). Low magnesium with high potassium supply changes sugar partitioning and root growth pattern prior to visible magnesium deficiency in leaves of rice Oryza sativa L. Am. J. Plant Sci. 02, 601-608. doi: 10.4236/ajps.2011.24071

Divol, F., Vilaine, F., Thibivilliers, S., Amselem, J., Palauqui, J. C., Kusiak, C., et al. (2005). Systemic response to aphid infestation by Myzus persicae in the phloem of Apium graveolens. Plant Mol. Biol. 57, 517-540. doi: 10.1007/s11103-005-0338-z

Dixon, A. F. G., and Wratten, S. D. (1971). Laboratory studies on aggregation, size and fecundity in the black bean aphid, Aphis fabae Scop. Bull. Entomol. Res. 61, 97-111. doi: 10.1017/S0007485300057485

Doehlemann, G., Molitor, F., and Hahn, M. (2005). Molecular and functional characterization of a fructose specific transporter from the gray mold fungus Botrytis cinerea. Fungal Genet. Biol. 42, 601-610. doi: 10.1016/j.fgb.2005.03.001

Doidy, J., Grace, E., Kuhn, C., SimonPlas, F., Casieri, L., and Wipf, D. (2012). Sugar transporters in plants and in their interactions with fungi. Trends Plant Sci. 17, 413-422. doi: 10.1016/j.tplants.2012.03.009

Draie, R., Péron, T., Pouvreau, J.-B., Véronési, C., Jégou, S., Delavault, P., et al. (2011). Invertases involved in the development of the parasitic plant Phelipanche ramosa: characterization of the dominant soluble acid isoform, PrSAI1. Mol. Plant Pathol. 12, 638-652. doi: 10.1111/j.13643703.2010.00702.x

Drake, B. G., Gonzàlez-Meler, M. A., and Long, S. P. (1997). More efficient plants: a consequence of rising atmospheric CO2? Annu. Rev. Plant Physiol. Mol. Biol. 48, 609-639. doi: 10.1146/annurev.arplant.48.1.609

Ehness, R., Ecker, M., Godt, D. E., and Roitsch, T. (1997). Glucose and stress independently regulate source and sink metabolism and defense mechanisms via signal transduction pathways involving protein phosphorylation. Plant Cell 9, 1825-1841. doi: 10.1105/tpc.9.10.1825

Eom, J. S., Cho, J. I., Reinders, A., Lee, S. W., Yoo, Y., Tuan, P. Q., et al. (2011). Impaired function of the tonoplastlocalized sucrose transporter in rice, OsSUT2, limits the transport of vacuolar reserve sucrose and affects plant growth. Plant Physiol. 157, 109-119. doi: 10.1104/pp.111.176982

Farrar, J. F., and Williams, M. L. (1991). The effects of increased atmospheric carbon dioxide and temperature on carbon partitioning, source-sink relations and respiration. Plant Cell Environ. 14, 819830. doi: 10.1111/j.1365-3040.1991. tb01445.x

Faucher, M., and Bonnemain, J. L. (1981). Action des barrières thermiques sur la circulation libérienne chez le Maïs (Zea mays L.). Physiol. Veg. 19, 379-390.

Faucher, M., Bonnemain, J. L., and Doffin, M. (1982). Effets des refroidissements localisés sur la circulation libérienne chez quelques espèces avec ou sans protéines- $\mathrm{P}$ et influence du mode de refroidissement. Physiol. Veg. 20, 395-405.

Fiehn, O. (2003). Metabolic networks of Cucurbita maxima phloem. Phytochemistry 62, 875-886. doi: 10.1016/S0031-9422(02)00715-X

Fiscus, E. L., Booker, F. L., and Burkey, K. O. (2005). Crop responses to ozone: uptake, modes of action, carbon assimilation and partitioning. Plant Cell Environ. 28, $997-$ 1011. doi: 10.1111/j.1365-3040.2005. 01349.x

Fisher, D. B., and Oparka, K. J. (1996). Post-phloem transport: principles and problems. J. Exp. Bot. 47, 1141-1154. doi: 10.1093/ jxb/47.Special_Issue.1141

Fotopoulos, V., Gilbert, M. J., Pittman, J. K., Marvier, A. C., Buchanan, A. J., Sauer, N., et al. (2003). The monosaccharide transporter gene, AtSTP4, and the cell-wall invertase, At $\beta$ fruct 1 , are induced in Arabidopsis during infection with the fungal biotroph Erysiphe cichoracearum. Plant Physiol. 132, 821-829. doi: 10.1104/pp.103.021428

Frost, C. J., Nyamdari, B., Tsai, C.J., and Harding, S. A. (2012). The tonoplast-localized sucrose transporter in Populus (PtaSUT4) regulates whole-plant water relations, responses to water stress, and photosynthesis. PLoS ONE 7:44467. doi: 10.1371/journal.pone.0044467

Furch, A. C. U., Hafke, J. B., Schulz, A., and Van Bel, A. J. E. (2007). Ca2(+ mediated remote control of reversible sieve tube occlusion in Vicia faba J. Exp. Bot. 58, 2827-2838. doi: 10.1093/jxb/erm 143

Gamalei, Y. V. (1991). Phloem loading and its development related to plant evolution from trees to herbs. Trees 5 , 50-64. doi: 10.1007/BF00225335

Gamalei, Y. V., Van Bel, A. J. E., Pakhomova, M. V., and Sjutkina, A. V. (1994). Effects of temperature on the conformation of the endoplasmic reticulum and on starch accumulation in leaves with the symplasmic minor-vein configuration. Planta 194, 443-453. doi: 10.1007/BF00714455

Gao, Z., Maurousset, L., Lemoine, R., Yoo, S. D., Van Nocker, S., and Loescher, W. (2003). Cloning, expression, and characterization of sorbitol transporters from developing sour cherry fruit and leaf sink tissues. Plant Physiol. 131, 1566-1575. doi: 10.1104/pp.102.016725

Geigenberger, P., Reimholz, R., Geiger, M., Merlo, L., Canale, V., and Stitt, M. (1997). Regulation of sucrose and starch metabolism in potato tubers in response to short-term water deficit. Planta 201, 502-518. doi: 10.1007/s004250050095

Gifford, R. M., Thorne, J. H., Hitz, W. D., and Giaquinta, R. T. (1984). Crop productivity and photoassimilate partitioning. Science 225, 801-808. doi: 10.1126/ science.225.4664.801
Gil, L., Yaron, I., Shalitin, D., Sauer, N., Turgeon, R., and Wolf, S. (2011). Sucrose transporter plays a role in phloem loading in CMVinfected melon plants that are defined as symplastic loaders. Plant J. 66, 366-374. doi: 10.1111/j.1365313X.2011.04498.x

Girousse, C., Bournoville, R., and Bonnemain, J. L. (1996). Water deficitinduced changes in concentrations in proline and some other amino acids in the phloem sap of alfalfa. Plant Physiol. 111, 109-113. doi: 10.1104/pp.111.1.109

Girousse, C., Faucher, M., Kleinpeter, C., and Bonnemain, J. L. (2003). Dissection of the effects of the aphid Acyrthosiphon pisum feeding on assimilate partitioning in Medicago sativa. New Phytol. 157, 8392. doi: 10.1046/j.1469-8137.2003. 00659.x

Girousse, C., Moulia, B., Silk, W., and Bonnemain, J. L. (2005). Aphid infestation causes different changes in carbon and nitrogen allocation in alfalfa stems as well as different inhibitions of longitudinal and radial expansion. Plant Physiol. 137, 1474-1484. doi: 10.1104/pp.104.057430

Godt, D., and Roitsch, T. (2006). The developmental and organ specific expression of sucrose cleaving enzymes in sugar beet suggests a transition between apoplasmic and symplasmic phloem unloading in the tap roots. Plant Physiol. Biochem. 44, 656-665. doi: 10.1016/ j.plaphy.2006.09.019

Gosalvez-Bernal, B., Genoves, A., Antonio Navarro, J., Pallas, V., and Sanchez-Pina, M. A. (2008). Distribution and pathway for phloem-dependent movement of Melon necrotic spot virus in melon plants. Mol. Plant Pathol. 9, 447461. doi: 10.1111/j.1364-3703.2008. 00474.x

Grams, T. E. E., Anegg, S., Häberle, K.H., Langebartels, C., and Matyssek, R. (1999). Interactions of chronic exposure to elevated $\mathrm{CO} 2$ and $\mathrm{O} 3 \mathrm{lev}$ els in the photosynthetic light and dark reactions of European beech (Fagus sylvatica). New Phytol. 144, 95-107.

Grantz, D. A. (2003). Ozone impacts on cotton: towards an integrated mechanism. Environ. Pollut. 126, 331344. doi: 10.1016/S0269-7491(03) 00246-X

Grantz, D. A., and Farrar, J. F. (1999). Acute exposure to ozone inhibits rapid carbon translocation from source leaves of Pima cotton. J. Exp. Bot. 50, 1253-1262. doi: $10.1093 / \mathrm{jxb} / 50.336 .1253$ 
Grantz, D. A., Gunn, S., and Vu, H. B. (2006). O3 impacts on plant development: a meta-analysis of root/shoot allocation and growth. Plant Cell Environ. 29, 1193-1209. doi: 10.1111/ j.1365-3040.2006.01521.x

Grantz, D. A., and Yang, S. (2000). Ozone impacts on allometry and root hydraulic conductance are not mediated by source limitation nor developmental age. J. Exp. Bot. 51, 919-927. doi: 10.1093/jexbot/51. 346.919

Grimmer, C., Bachfischer, T., and Komor, E. (1999). Carbohydrate partitioning into starch in leaves of Ricinus communis L. grown under elevated $\mathrm{CO} 2$ is controlled by sucrose. Plant Cell Environ. 22, 1275-1280. doi: 10.1046/j.13653040.1999.00481.x

Grimmer, C., and Komor, E. (1999). Assimilate export by leaves of Ricinus communis L. growing under normal and elevated carbon dioxide concentrations: the same rate during the day, a different rate at night. Planta 209, 275-281. doi: 10.1007/ s004250050633

Hafke, J. B., Van Amerongen, J. K., Kelling, F., Furch, A. C., Gaupels, F., and Van Bel, A. J. E. (2005). Thermodynamic battle for photosynthate acquisition between sieve tubes and adjoining parenchyma in transport phloem. Plant Physiol. 138, 1527-1537. doi: 10.1104/pp.104. 058511

Hall, J. L., and Williams, L. E. (2000). Assimilate transport and partitioning in fungal biotrophic interactions. Funct. Plant Biol. 27, 549-560. doi: 10.1071/PP99140

Hammond, J. P., and White, P. J. (2008). Sucrose transport in the phloem: integrating root responses to phosphorus starvation. J. Exp. Bot. 59, 93-109. doi: 10.1093/jxb/erm221

Harloff, H. J., and Wegmann, K. (1993). Evidence for a mannitol cycle in Orobanche ramosa and Orobanche crenata. J. Plant Physiol. 141, 513-520. doi: 10.1016/S01761617(11)80449-9

Haupt, S., Oparka, K. J., Sauer, N., and Neumann, S. (2001). Macromolecular trafficking between Nicotiana tabacum and the holoparasite Cuscuta reflexa. J. Exp. Bot. 52, 173-177. doi: 10.1093/jexbot/52.354.173

Hawkins, C. D. B., Whitecross, M. I., and Aston, M. J. (1987). The effect of short-term aphid feeding on the partitioning of $14 \mathrm{CO} 2$ photoassimilate in three legume species. Can. J. Bot. 65, 666-672. doi: 10.1139/b87-089

Hayes, M. A., Feechan, A., and Dry, I. B. (2010). Involvement of abscisic acid in the coordinated regulation of a stress-inducible hexose transporter (VvHT5) and a cell wall invertase in grapevine in response to biotrophic fungal infection. Plant Physiol. 153, 211-221. doi: 10.1104/pp.110.154765

Helber, N., Wippel, K., Sauer, N., Schaarschmidt, S., Hause, B., and Requena, N. (2011). A versatile monosaccharide transporter that operates in the arbuscular mycorrhizal fungus Glomus sp. is crucial for the symbiotic relationship with plants. Plant Cell 23, 3812-3823. doi: 10.1105/tpc.111.089813

Herbers, K., Meuwly, P., Frommer, W. B., Metraux, J. P., and Sonnewald, U. (1996). Systemic acquired resistance mediated by the ectopic expression of invertase: possible hexose sensing in the secretory pathway. Plant Cell 8, 793-803. doi: 10.1105/tpc.8.5.793

Herbers, K., Takahata, Y., Melzer, M., Mock, H. P., Hajirezaei, M. and Sonnewald, U. (2000). Regulation of carbohydrate partitioning during the interaction of potato virus Y with tobacco. Mol. Plant Pathol. 1, 51-59. doi: 10.1046/j.13643703.2000.00007.x

Hermans, C., Bourgis, F., Faucher, M., Strasser, R. J., Delrot, S., and Verbruggen, N. (2005). Magnesium deficiency in sugar beets alters sugar partitioning and phloem loading in young mature leaves. Planta 220 541-549. doi: 10.1007/s00425-0041376-5

Hermans, C., Hammond, J. P., White, P. J., and Verbruggen, N. (2006). How do plants respond to nutrient shortage by biomass allocation? Trends Plant Sci. 11, 610-617. doi 10.1016/j.tplants.2006.10.007

Hermans, C., Johnson, G. N. Strasser, R. J., and Verbruggen, N. (2004). Physiological characterisation of magnesium deficiency in sugar beet: acclimation to low magnesium differentially affects photosystems I and II. Planta 220, 344-355. doi: 10.1007/s00425-0041340-4

Hewer, A., Will, T., and Van Bel, A. J. E. (2010). Plant cues for aphid navigation in vascular tissues. J. Exp. Bot. 213, 4030-4042. doi: 10.1242/jeb.046326

Hibberd, J. M., and Jeschke, W. D. (2001). Solute flux into parasitic plants. J. Exp. Bot. 52, 2043-2049. doi: 10.1093/jexbot/52.363.2043

Ho, L. C. (1988). Metabolism and compartmentation of imported sugars in sink organs in relation to sink strength. Annu. Rev. Plant Physiol. Mol. Biol. 39, 355-378. doi: 10.1146/annurev.pp.39.060188 002035

Hoffmann-Thoma, G., Van Bel, A. J. E., and Ehlers, K. (2001). Ultrastructure of minor-vein phloem and assimilate export in summer and winter leaves of symplasmatically loading evergreens Ajuga reptans L., Aucuba japonica Thunb., and Hedera helix L. Planta 212, 231-242. doi: $10.1007 / \mathrm{s} 004250000382$

Hofius, D., Hajirezaei, M. R., Geiger, M., Tschiersch, H., Melzer, M. and Sonnewald, U. (2004). RNAimediated tocopherol deficiency impairs photoassimilate export in transgenic potato plants. Plant Physiol. 135, 1256-1268. doi: 10.1104/ pp.104.043927

Hofius, D., Herbers, K., Melzer, M., Omid, A., Tacke, E., Wolf, S. et al. (2001). Evidence for expression level-dependent modulation of carbohydrate status and viral resistance by the potato leafroll virus movement protein in transgenic tobacco plants. Plant J. 28, 529-543. doi: 10.1046/j.1365-313X.2001.01179.x

Hou, W. (1985). Seasonal fluctuation of reserve materials in the trunkwood of spruce [Picea abies (L.) Karst]. J. Plant Physiol. 117, 355-362. doi: 10.1016/S0176-1617(85)80071-7

Huglin, P. (1986). Biologie et écologie de la vigne. Paris: INRA Payot Lausanne, Techniques and Documentation

Hummel, I., Pantin, F., Sulpice, R., Piques, M., Rolland, G., Dauzat, M., et al. (2010). Arabidopsis plants acclimate to water deficit at low cost through changes of carbon usage: an integrated perspective using growth, metabolite, enzyme, and gene expression analysis. Plant Physiol. 154, 357 372. doi: 10.1104/pp.110.157008

Ibraheem, O., Dealtry, G., Roux, S., and Bradley, G. (2011). The effect of drought and salinity on the expressional levels of sucrose transporters in rice (Oryza sativa Nipponbare) cultivar plants. Plant Omics J. 4, 68-74.

Jeschke, W. D., Bäumel, P., Räth, N., Czygan, F.-C., and Proksch, P. (1994). Modelling of the flows and partitioning of carbon and nitrogen in the holoparasite Cuscuta reflexa Roxb. and its host Lupinus albus L.: II. Flows between host and parasite and within the parasitized host. J. Exp. Bot. 45, 801-812.

Juchaux-Cachau, M., LandouarArsivaud, L., Pichaut, J. P., Campion, C., Porcheron, B., Jeauffre, J., et al (2007). Characterization of AgMaT2, a plasma membrane mannitol transporter from celery, expressed in phloem cells, including phloem parenchyma cells. Plant Physiol. 145, 62-74. doi: 10.1104/pp.107.103143

Kangasjärvi, J., Talvinen, J., Utriainen, M., and Karjalainen, R. (1994). Plant defence systems induced by ozone. Plant Cell Environ. 17, 783-794. doi: 10.1111/j.1365-3040. 1994.tb00173.x

Kehr, J. (2013). Systemic regulation of mineral homeostasis by micro RNAs. Front. Plant Sci. 4:145. doi: 10.3389/fpls.2013.00145

Kim, J.-Y., Mahé, A., Brangeon, J., and Prioul, J.-L. (2000). A maize vacuolar invertase, IVR2, is induced by water stress. Organ/tissue specificity and diurnal modulation of expression. Plant Physiol. 124, 71-84. doi: 10.1104/pp.124.1.71

Knoblauch, M., and Oparka, K. (2012). The structure of the phloem-still more questions than answers. Plant J. 70, 147-156. doi: 10.1111/j.1365313X.2012.04931.x

Kocal, N., Sonnewald, U., and Sonnewald, S. (2008). Cell wall-bound invertase limits sucrose export and is involved in symptom development and inhibition of photosynthesis during compatible interaction between tomato and Xanthomonas campestris pv vesicatoria. Plant Physiol. 148, 1523-1536. doi: 10.1104/pp.108.127977

Koch, K. (2004). Sucrose metabolism: regulatory mechanisms and pivotal roles in sugar sensing and plant development. Curr. Opin. Plant Biol. 7, 235-246. doi: 10.1016/ j.pbi.2004.03.014

Koster, K. L., and Leopold, A. C. (1988). Sugars and desiccation tolerance in seeds. Plant Physiol. 88, 829-832. doi: 10.1104/pp.88.3.829

Krupa, S. V., and Manning, W. J. (1988). Atmospheric ozone-formation and effects on vegetation. Environ. Pollut. 50, 101-137. doi: 10.1016/02697491(88)90187-X

Kurczyńska, E. U., Dmuchowski, W., Włoch, W., and Bytnerowicz, A. (1997). The influence of air pollutants on needles and stems of scots pine (Pinus Sylvestris L.) trees. Environ. Pollut. 98, 325334. doi: 10.1016/S0269-7491(97) 00141-3

Lalonde, S., Wipf, D., and Frommer, W. B. (2004). Transport mechanisms for organic forms of carbon and nitrogen between source and sink. Annu. Rev. Plant Biol. 55, 341-372. doi: 10.1146/annurev.arplant.55.031903. 141758

Landouar-Arsivaud, L., JuchauxCachau, M., Jeauffre, J., Biolley, J.-P., Maurousset, L., and Lemoine, R. M. (2011). The promoters of 3 
celery salt-induced phloem-specific genes as new tools for monitoring salt stress responses. Plant Physiol. Biochem. 49, 2-8. doi: 10.1016/ j.plaphy.2010.09.008

Lang, A., and Minchin, P. E. H. (1986). Phylogenetic distribution and mechanism of translocation inhibition by chilling. J. Exp. Bot. 37, 389-398. doi: 10.1093/jxb/37.3.389

Lebon, E., Pellegrino, A., Louarn, G., and Lecoeur, J. (2006). Branch development controls leaf area dynamics in grapevine (Vitis vinifera) growing in drying soil. Ann. Bot. 98, 175-185. doi: 10.1093/aob/mcl085

Lecoeur, J., Wery, J., Turc, O., and Tardieu, F. (1995). Expansion of pea leaves subjected to short water deficit: cell number and cell size are sensitive to stress at different periods of leaf development. J. Exp. Bot. 46, 1093 1101. doi: 10.1093/jxb/46.9.1093

Lee-Ho, E., Walton, L. J., Reid, D. M., Yeung, E. C., and Kurepin, L. V. (2007). Effects of elevated carbon dioxide and sucrose concentrations on Arabidopsis thaliana root architecture and anatomy. Can. J. Bot. 85, 324-330. doi: 10.1139/B07-009

Lei, M., Liu, Y., Zhang, B., Zhao, Y., Wang, X., Zhou, Y., et al. (2011). Genetic and genomic evidence that sucrose is a global regulator of plant responses to phosphate starvation in Arabidopsis. Plant Physiol. 156, 11161130. doi: 10.1104/pp.110.171736

Lingner, U., Munch, S., Deising, H. B., and Sauer, N. (2011). Hexose transporters of a hemibiotrophic plant pathogen: functional variations and regulatory differences at different stages of infection. J. Biol. Chem. 286, 20913-20922. doi: 10.1074/jbc.M110.213678

Liu, D. D., Chao, W. M., and Turgeon, R. (2012). Transport of sucrose, not hexose, in the phloem. J. Exp. Bot. 63, 4315-4320. doi: 10.1093/jxb/ers127

Liu, J., Samac, D. A., Bucciarelli, B., Allan, D. L., and Vance, C. P. (2005) Signaling of phosphorus deficiencyinduced gene expression in white lupin requires sugar and phloem transport. Plant J. 41, 257-268. doi: 10.1111/j.1365-313X.2004.02289.x

Lloyd, J. C., and Zakhleniuk, O. V. (2004). Responses of primary and secondary metabolism to sugar accumulation revealed by microarray expression analysis of the Arabidopsis mutant, pho3. J. Exp. Bot. 55, 1221-1230. doi: 10.1093/jxb/erh143

Lohaus, G., Hussmann, M., Pennewiss, K., Schneider, H., Zhu, J. Ä., and Sattelmacher, B. (2000). Solute balance of a maize (Zea mays L.) source leaf as affected by salt treatment with special emphasis on phloem retranslocation and ion leaching. J. Exp. Bot. 51, 1721-1732. doi: 10.1093/jexbot/51.351.172

Lorenc-Plucinska, G., and Ziegler, $\mathrm{H}$. (1987). Effect of sulfite and sulfhydryl reagents on the phloem loading in cotyledons of Ricinus communis $\mathrm{L}$. J. Plant Physiol. 128, 417-424. doi: 10.1016/S0176-1617(87)80126-8

Lucas, W. J., and Wolf, S. (1999). Connections between virus movement, macromolecular signaling and assimilate allocation. Curr. Opin. Plant Biol. 2, 192-197. doi: 10.1016/S13695266(99)80035-1

Lundmark, M., Cavaco, A. M., Trevanion, S., and Hurry, V. (2006). Carbon partitioning and export in transgenic Arabidopsis thaliana with altered capacity for sucrose synthesis grown at low temperature: a role for metabolite transporters. Plant Cell Environ. 29, 1703-1714. doi: 10.1111/j.1365-3040.2006.01543.x

Maeda, H., Song, W., Sage, T. L., and Dellapenna, D. (2006). Tocopherols play a crucial role in low-temperature adaptation and phloem loading in Arabidopsis. Plant Cell 18, 2710-2732. doi: 10.1105/tpc.105.039404

Makino, A., and Mae, T. (1999). Photosynthesis and plant growth at elevated levels of CO2. Plant Cell Physiol. 40, 999-1006. doi: 10.1093/oxfordjournals.pcp.a029493

Marschner, H., Kirkby, E. A., and Cakmak, I. (1996). Effect of mineral nutritional status on shootroot partitioning of photoassimilates and cycling of mineral nutrients. J. Exp. Biol. 47, 1255-1263. doi: 10.1093/jxb/47.Special_Issue. 1255

Martin, T., Oswald, O., and Graham, I. A. (2002). Arabidopsis seedling growth, storage lipid mobilization, and photosynthetic gene expression are regulated by carbon:nitrogen availability. Plant Physiol. 128, 472481. doi: 10.1104/pp.010475

Maurousset, L., Lemoine, R., Gallet, O., Delrot, S., and Bonnemain, J.L. (1992a). Sulfur dioxide inhibits the sucrose carrier of the plant plasma membrane. BBA Biomembranes 1105, 230-236. doi: 10.1016/ 0005-2736(92)90199-V

Maurousset, L., Raymond, P. Caudillert, M., and Bonnemain, J.-L. (1992b). Mechanism of the inhibition of phloem loading by sodium sulfite: effect of the pollutant on respiration, photosynthesis and energy charge in the leaf tissues. Physiol. Plant. 84, 101-105. doi: 10.1111/j.1399-3054.1992.tb08771.x Mendgen, K., and Hahn, M. (2002). Plant infection and the establishment of fungal biotrophy. Trends Plant Sci. 7, 352-356. doi: 10.1016/S13601385(02)02297-5

Mendoza-Cozatl, D. G., Jobe, T. O., Hauser, F., and Schroeder, J. I. (2011). Long-distance transport, vacuolar sequestration, tolerance, and transcriptional responses induced by cadmium and arsenic. Curr. Opin. Plant Biol. 14, 554-562. doi: 10.1016/j.pbi.2011.07.004

Merchant, A., and Richter, A. A. (2011). Polyols as biomarkers and bioindicators for 21st century plant breeding. Funct. Plant Biol. 38, 934-940. doi: 10.1071/FP11105

Mewis, I., Khan, M. A. M., Glawischnig, E., Schreiner, M., and Ulrichs, C. (2012). Water stress and aphid feeding differentially influence metabolite composition in Ara bidopsis thaliana (L.). PLoS ONE 7:48661. doi: 10.1371/journal.pone. 0048661

Miles, P. W. (1989). "The responses of plant to the feeding of Arabidopsis: principles," in Minks, Aphids, Natural Enemies and Control ed. A. K. Herrawyn (Elsevier: Amsterdam), $1-21$.

Miles, P. W. (1999). Aphid saliva. Biol. Rev. 74, 41-85. doi: 10.1017/ S0006323198005271

Minchin, P. E. H., and Gould, R (1986). Effect of SO2 on phloem loading. Plant Sci. 43, 179-183. doi: 10.1016/0168-9452(86)90015-4

Minchin, P. E. H., and Thorpe, M. R. (1987). Measurement o unloading and reloading of photoassimilate within the stem of bean. J. Exp. Bot. 38, 211-220. doi: 10.1093/jxb/38.2.211

Minchin, P. E. H., Thorpe, M. R., Farrar, J. F., and Koroleva, O. A. (2002) Source and sink coupling in young barley plants and control of phloem loading. J. Exp. Bot. 53, 1671-1676. doi: 10.1093/jxb/erf003

Moran, P. J., and Thompson, G. A. (2001). Molecular responses to aphid feeding in Arabidopsis in relation to plant defense pathways. Plant Physiol. 125, 1074-1085. doi: 10.1104/pp.125.2.1074

Mortensen, L., and Engvild, K. C. (1995). Effects of ozone on 14C translocation velocity and growth of spring wheat (Triticum aestivum L.) exposed in open-top chambers. Environ. Pollut. 87, 135-140. doi: 10.1016/0269-7491(94)P2599-5

Muller, B., Pantin, F., Genard, M., Turc, O., Freixes, S., Piques, M., et al. (2011). Water deficits uncouple growth from photosynthesis, increase $\mathrm{C}$ content, and modify the relationships between $\mathrm{C}$ and growth in sink organs. J. Exp. Bot. 62, 1715-1729. doi: $10.1093 /$ jxb/erq438

Nadler-Hassar, T., Goldshmidt, A., Rubin, B., and Wolf, S. (2004). Glyphosate inhibits the translocation of green fluorescent protein and sucrose from a transgenic tobacco host to Cuscuta campestris Yunk. Planta 219, 790-796. doi: 10.1007/ s00425-004-1288-4

Newton, A. C., Fitt, B. D. L., Atkins, S. D., Walters, D. R., and Daniell, T. J. (2010). Pathogenesis, parasitism and mutualism in the trophic space of microbe-plant interactions. Trends Microbiol. 18, 365-373. doi: 10.1016/j.tim.2010.06.002

Noiraud, N., Maurousset, L., and Lemoine, R. (2001a). Identification of a mannitol transporter, AgMaT1, in celery phloem. Plant Cell 13, 695-705. doi: 10.1105/tpc.13.3.695

Noiraud, N., Maurousset, L., and Lemoine, R. M. (2001b). Transport of polyols in higher plants. Plant Physiol. Biochem. 39, 717-728. doi: 10.1016/S0981-9428(01)01292-X

Olesinski, A. A., Almon, E., Navot, N., Perl, A., Galun, E., Lucas, W. J., et al. (1996). Tissue-specific expression of the tobacco mosaic virus movement protein in transgenic potato plants alters plasmodesmal function and carbohydrate partitioning. Plant Physiol. 111, 541-550. doi: 10.1104/pp.111.2.541

Panstruga, R. (2003). Establishing compatibility between plants and obligate biotrophic pathogens. Curr. Opin. Plant Biol. 6, 320-326. doi: 10.1016/S1369-5266(03)00043-8

Patrick, J. W. (1997). PHLOEM UNLOADING: sieve element unloading and post-sieve element transport. Annu. Rev. Plant Physiol. Plant Mol. Biol. 48, 191-222. doi: 10.1146/annurev.arplant.48.1.191

Pattanagul, W., and Madore, M. A. (1999). Water deficit effects on raffinose family oligosaccharide metabolism in Coleus. Plant Physiol. 121, 987-993. doi: 10.1104/ pp.121.3.987

Paul, M. J., and Driscoll, S. P. (1997). Sugar repression of photosynthesis: the role of carbohydrates in signalling nitrogen deficiency through source:sink imbalance. Plant Cell Environ. 20, 110-116. doi: $\quad$ 10.1046/j.1365-3040.1997. d01-17.x

Pell, E. J., and Dann, M. S. (1991). "Multiple stress induced foliar senescence and implications for whole," in Response of Plants to Multiples Stress, eds H. A. Mooney, W. E. Winner and E. J. Pell (San Diego C.A: Academic Press), 189-204. 
Pelleschi, S., Rocher, J. P., and Prioul, J. L. (1997). Effect of water restriction on carbohydrate metabolism and photosynthesis in mature maize leaves. Plant Cell Environ. 20, 493-503. doi: 10.1046/ j.1365-3040.1997.d01-89.x

Péron, T., Véronési, C., Mortreau, E., Pouvreau, J.-B., Thoiron, S., Leduc, N., et al. (2012). Role of the sucrose synthase encoding PrSusl gene in the development of the parasitic plant Phelipanche ramosa L. (Pomel). Mol. Plant Microbe Interact. 25, 402-411. doi: 10.1094/MPMI-10-11-0260

Peuke, A. D. (2010). Correlations in concentrations, xylem and phloem flows, and partitioning of elements and ions in intact plants. A summary and statistical re-evaluation of modelling experiments in Ricinus communis. J. Exp. Bot. 61, 635-655. doi: 10.1093/jxb/erp352

Peuke, A. D., Hartung, W., and Jeschke, W. D. (1994). The uptake and flow of $\mathrm{C}, \mathrm{N}$ and ions between roots and shoots in Ricinus communis L. II. Grown with low or high nitrate supply. J. Exp. Bot. 45, 733-740. doi: 10.1093/jxb/45.6.733

Peuke, A. D., Windt, C., and Van As, H. (2006). Effects of coldgirdling on flows in the transport phloem in Ricinus communis: is mass flow inhibited? Plant Cell Environ. 29, 15-25. doi: 10.1111/j.13653040.2005.01396.x

Pickard, W. F., and Minchin, P. E. H. (1990). The transient inhibition of phloem translocation in Phaseolus vulgaris by abrupt temperature drops, vibration, and electric shock. J. Exp. Bot. 41, 1361-1369. doi: 10.1093/jxb/41.11.1361

Pinheiro, C., Chaves, M. M., and Ricardo, C. P. (2001). Alterations in carbon and nitrogen metabolism induced by water deficit in the stems and leaves of Lupinus albus L. J. Exp. Bot. 52, 1063-1070. doi: 10.1093/jexbot/52.358.1063

Pinheiro, C., Rodrigues, A. P., De Carvalho, I. S., Chaves, M. M., and Ricardo, C. P. (2005). Sugar metabolism in developing lupin seeds is affected by a short-term water deficit. J. Exp. Bot. 56, 2705-2712. doi: $10.1093 /$ jxb/eri263

Pleijel, H., and Uddling, J. (2012). Yield vs. Quality trade-offs for wheat in response to carbon dioxide and ozone. Glob. Change Biol. 18, 596-605. doi: 10.1111/j.13652486.2011.2489.x

Pommerrenig, B., Papini-Terzi, F. S., and Sauer, N. (2007). Differential regulation of sorbitol and sucrose loading into the phloem of Plantago major in response to salt stress. Plant Physiol. 144, 1029-1038. doi: 10.1104/pp.106.089151

Puckett, K. J., Nieboer, E., Flora, W. P., and Richardson, D. H. S. (1973). Sulphur dioxide: its effect on photo-synthetic $14 \mathrm{C}$ fixation in lichens and suggested mechanisms of phytotoxicity. New Phytol. 72, 141154. doi: 10.1111/j.1469-8137.1973. tb02019.x

Reinders, A., Sivitz, A. B., and Ward, J. M. (2012). Evolution of plant sucrose uptake transporters. Front. Plant Sci. 3:22. doi: 10.3389/fpls. 2012.00022

Remans, T., Nacry, P., Pervent, M., Girin, T., Tillard, P., Lepetit, M. et al. (2006). A central role for the nitrate transporter NRT2.1 in the integrated morphological and physiological responses of the root system to nitrogen limitation in Arabidopsis. Plant Physiol. 140, 909-921. doi: 10.1104/pp.105.075721

Rennie, E. A., and Turgeon, R. (2009). A comprehensive picture of phloem loading strategies. Proc. Natl. Acad. Sci. U.S.A. 106, 14162-14167. doi: 10.1073/pnas.0902279106

Rizhsky, L., Liang, H., Shuman, J. Shulaev, V., Davletova, S., and Mittler, R. (2004). When defense pathways collide. The response of Arabidopsis to a combination of drought and heat stress. Plant Physiol. 134, 1683-1696. doi: 10.1104/pp.103. 033431

Roitsch, T. (1999). Source-sink regulation by sugar and stress. Curr. Opin. Plant Biol. 2, 198206. doi: 10.1016/S1369-5266(99) 80036-3

Roitsch, T., Balibrea, M. E., Hofmann, M., Proels, R., and Sinha, A. K. (2003). Extracellular invertase: key metabolic enzyme and PR protein. J. Exp. Bot. 54, 513-524. doi: 10.1093/jxb/erg050

Roitsch, T., and Gonzalez, M. C. (2004). Function and regulation of plant invertases: sweet sensations. Trends Plant Sci. 9, 606-613. doi: 10.1016/j.tplants.2004.10.009

Rolland, F., Baena-Gonzalez, E., and Sheen, J. (2006). Sugar sensing and signaling in plants: conserved and novel mechanisms. Аnnu. Rev. Plant Biol. 57, 675-709. doi: 10.1146/annurev.arplant.57.032905. 105441

Ruiz, E., and Ruffner, H. P. (2002). Immunodetection of Botrytisspecific invertase in infected grapes. J. Phytopathol. 150, 76-85. doi: 10.1046/j.1439-0434.2002.00720.x

Sandermann, H. (1996). Ozone and plant health. Annu. Rev. Phytopathol.
34, 347-366. doi: 10.1146/ annurev.phyto.34.1.347

Sauer, N. (2007). Molecular physiology of higher plant sucrose transporters. FEBS Lett. 581, 2309-2317. doi: 10.1016/j.febslet.2007.03.048

Saxe, H., and Murali, N. S. (1989). Diagnostic parameters for selecting against novel spruce (Picea abies) decline: I. Tree morphology and photosynthesis response to acute $\mathrm{SO} 2$ exposures. Physiol. Plant. 76, 340-348. doi: 10.1111/j.13993054.1989.tb06201.x

Scheible, W.-R., Lauerer, M., Schulze, E.-D., Caboche, M., and Stitt, M. (1997). Accumulation of nitrate in the shoot acts as a signal to regulate shoot-root allocation in tobacco. Plant J. 11, 671691. doi: 10.1046/j.1365-313X.1997. 11040671.x

Schnyder, H. (1993). The role of carbohydrate storage and redistribution in the source-sink relations of wheat and barley during grain filling - a review. New Phytol. 123, 233-245. doi: 10.1111/j.14698137.1993.tb03731.x

Schoelz, J. E., Harries, P. A., and Nelson, R. S. (2011). Intracellular transport of plant viruses: finding the door out of the cell. Mol. Plant 4,813-831. doi: $10.1093 / \mathrm{mp} / \mathrm{ssr} 070$

Schrier, A., Hoffmann-Thoma, G., and Van Bel, A. J. E. (2000). Temperature effects on symplasmic and apoplasmic phloem loading and loadingassociated carbohydrate processing. Aust. J. Plant Physiol. 27, 769-778. doi: 10.1071/PP99166

Schroeder, J. I., Delhaize, E., Frommer, W. B., Guerinot, M. L., Harrison, M. J., Herrera-Estrella, L., et al. (2013). Using membrane transporters to improve crops for sustainable food production. Nature 497, 60-66. doi: 10.1038/nature11909

Schulz, A., Beyhl, D., Marten, I., Wormit, A., Neuhaus, E., Poschet, G. et al. (2011). Proton-driven sucrose symport and antiport are provided by the vacuolar transporters SUC4 and TMT1/2. Plant J. 68, 129-136. doi: 10.1111/j.1365-313X.2011.04672.x

Shalitin, D., and Wolf, S. (2000). Cucumber Mosaic Virus infection affects sugar transport in melon plants. Plant Physiol. 123, 597-604. doi: 10.1104/pp.123.2.597

Siemens, J., Gonzalez, M. C., Wolf, S., Hofmann, C., Greiner, S., Du, Y., et al. (2011). Extracellular invertase is involved in the regulation of clubroot disease in Arabidopsis thaliana. Mol. Plant Pathol. 12, 247 262. doi: 10.1111/j.1364-3703.2010. 00667.x
Singh, V., Louis, J., Ayre, B. G., Reese, J. C., Pegadaraju, V., and Shah, J. (2011). TREHALOSE PHOSPHATE SYNTHASE11-dependent trehalose metabolism promotes Arabidopsis thaliana defense against the phloemfeeding insect Myzus persicae. Plant J. 67, 94-104 . doi: 10.1111/j.1365313X.2011.04583.x

Slewinski, T. L. (2011). Diverse functional roles of monosaccharide transporters and their homologs in vascular plants: a physiological perspective. Mol. Plant 4, 641-662. doi: 10.1093/mp/ssr051

Smith, S. E., and Smith, F. A. (2012). Fresh perspectives on the roles of arbuscular mycorrhizal fungi in plant nutrition and growth. Mycologia 104, 1-13. doi: 10.3852/11-229

Stockwell, W. R., Kirchner, F., Kuhn, M., and Seefeld, S. (1997). A new mechanism for regional atmospheric chemistry modeling. J. Geophys. Res. Atmos. 102, 25847-25879. doi: 10.1029/97JD00849

Stoop, J. M. H., Williamson, J. D., and Mason Pharr, D. (1996). Mannitol metabolism in plants: a method for coping with stress. Trends Plant Sci. 1, 139-144. doi: 10.1016/S13601385(96)80048-3

Sutton, P. N., Gilbert, M. J., Williams, L. E., and Hall, J. L. (2007). Powdery mildew infection of wheat leaves changes host solute transport and invertase activity. Physiol. Plant. 129, 787-795. doi: 10.1111/j.13993054.2007.00863.x

Sutton, P. N., Henry, M. J., and Hall, J. L. (1999). Glucose, and not sucrose, is transported from wheat to wheat powdery mildew. Planta 208, 426-430. doi: 10.1007/s0042500 50578

Suwa, R., Fujimaki, S., Suzui, N., Kawachi, N., Ishii, S., Sakamoto, K., et al. (2008). Use of positronemitting tracer imaging system for measuring the effect of salinity on temporal and spatial distribution of $11 \mathrm{C}$ tracer and coupling between source and sink organs. Plant Sci. 175, 210-216. doi: 10.1016/ j.plantsci.2008.03.022

Taji, T., Ohsumi, C., Iuchi, S., Seki, M., Kasuga, M., Kobayashi, M., et al. (2002). Important roles of drought- and cold-inducible genes for galactinol synthase in stress tolerance in Arabidopsis thaliana. Plant J. 29, 417-426. doi: 10.1046/j.09607412.2001.01227.x

Talbot, N. J. (2010). Living the sweet life: how does a plant pathogenic fungus acquire sugar from plants? PLoS Biol. 8:1000308. doi: 10.1371/journal.pbio. 1000308 
Tecsi, L. I., Smith, A. M., Maule, A. J., and Leegood, R. C. (1996). A spatial analysis of physiological changes associated with infection of cotyledons of marrow plants with cucumber mosaic virus. Plant Physiol. 111, 975-985. doi: 10.1104/pp.111.4.975

Thorpe, M. R., Furch, A. C., Minchin, P. E., Föller, J., Van Bel, A. J., and Hafke, J. B. (2010). Rapid cooling triggers forisome dispersion just before phloem transport stops. Plant Cell Environ. 33, 259-271. doi: 10.1111/j.1365-3040.2009.02079.x

Tjallingii, W. F. (2006). Salivary secretions by aphids interacting with proteins of phloem wound responses. J. Exp. Bot. 57, 739-745. doi: 10.1093/jxb/erj088

Trouverie, J., Chateau-Joubert, S., Thevenot, C., Jacquemot, M. P., and Prioul, J. L. (2004). Regulation of vacuolar invertase by abscisic acid or glucose in leaves and roots from maize plantlets. Planta 219, 894-905. doi: 10.1007/s00425-004-1289-3

Truernit, E., Schmid, J., Epple, P., Illig, J., and Sauer, N. (1996). The sink-specific and stress-regulated Arabidopsis STP4 gene: enhanced expression of a gene encoding a monosaccharide transporter by wounding, elicitors, and pathogen challenge. Plant Cell 8, 2169-2182. doi: 10.1105/tpc.8.12.2169

Turgeon, R. (2010a). The puzzle of phloem pressure. Plant Physiol. 154, 578-581. doi: 10.1104/ pp. 110.161679

Turgeon, R. (2010b). The role of phloem loading reconsidered. Plant Physiol. 152, 1817-1823. doi: 10.1104/pp.110.153023

Uraguchi, S., Kamiya, T., Sakamoto, T., Kasai, K., Sato, Y., Nagamura, Y., et al. (2011). Low-affinity cation transporter (OsLCT1) regulates cadmium transport into rice grains. Proc. Natl. Acad. Sci. U.S.A. 108, 20959-20964. doi: 10.1073/pnas.1116531109

Van Bel, A. J. E. (2003). The phloem, a miracle of ingenuity. Plant Cell Environ. 26, 125-149. doi: 10.1046/j.1365-3040.2003.00963.x

Van Bel, A. J. E., and Gamalei, Y. V. (1992). Ecophysiology of phloem loading in source leaves. Plant Cell Environ. 15, 265-270. doi: 10.1111/j.1365-3040.1992.tb00973.x van Bel, A. J. E., and Hess, P. H. (2008). Hexoses as phloem transport sugars: the end of a dogma? J. Exp. Bot. 59, 261-272. doi: 10.1093/jxb/erm294

van Kan, J. A. (2006). Licensed to kill: the lifestyle of a necrotrophic plant pathogen. Trends Plant Sci. 11, 247-253. doi: 10.1016/ j.tplants.2006.03.005
Viola, R., Roberts, A. G., Haupt, S., Gazzani, S., Hancock, R. D., Marmiroli, N., et al. (2001). Tuberization in potato involves a switch from apoplastic to symplastic phloem unloading. Plant Cell 13, 385-398. doi: 10.1105/tpc.13.2.385

Voegele, R., and Mendgen, K. (2011). Nutrient uptake in rust fungi: how sweet is parasitic life? Euphytica 179, 41-55. doi: 10.1007/s10681-0110358-5

Voegele, R. T., Struck, C., Hahn, M., and Mendgen, K. (2001). The role of haustoria in sugar supply during infection of broad bean by the rust fungus Uromyces fabae. Proc. Natl. Acad. Sci. U.S.A. 98, 8133-8138. doi: 10.1073/pnas. 131186798

Voegele, R. T., Wirsel, S., Moll, U., Lechner, M., and Mendgen, K. (2006). Cloning and characterization of a novel invertase from the obligate biotroph Uromyces fabae and analysis of expression patterns of host and pathogen invertases in the course of infection. Mol. Plant Microbe Interact. 19, 625-634. doi: 10.1094/MPMI-190625

Voelckel, C., Weisser, W. W., and Baldwin, I. T. (2004). An analysis of plant-aphid interactions by different microarray hybridization strategies. Mol. Ecol. 13, 3187-3195. doi: 10.1111/j.1365-294X.2004.02297.x

Vollenweider, P., Cosio, C., GünthardtGoerg, M. S., and Keller, C. (2006). Localization and effects of cadmium in leaves of a cadmiumtolerant willow (Salix viminalis L.). Environ. Exp. Bot. 58, 2540. doi: 10.1016/j.envexpbot.2005. 06.012

Volz, A., and Kley, D. (1988). Evaluation of the Montsouris series of ozone measurements made in the 19th-century. Nature 332, 240-242. doi: 10.1038/332240a0

Wahl, R., Wippel, K., Goos, S. Kamper, J., and Sauer, N. (2010). A novel high-affinity sucrose transporter is required for virulence of the plant pathogen Ustilago maydis. PLoS Biol. 8:1000303. doi: 10.1371/journal.pbio. 1000303

Wang, N., and Nobel, P. S. (1996). Doubling the $\mathrm{CO} 2$ concentration enhanced the activity of carbohydrate-metabolism enzymes, source carbohydrate production, photoassimilate transport, and sink strength for Opuntia ficus-indica. Plant Physiol. 110, 893-902.

Wardlaw, I. F. (1990). Tansley Review No. 27 The control of carbon partitioning in plants. New Phytol. 116, 341-381. doi: 10.1111/j.14698137.1990.tb00524.x
Way, D. A., Ladeau, S. L., Mccarthy, H. R., Clark, J. S., Oren, R. A. M., Finzi, A. C., et al. (2010). Greater seed production in elevated $\mathrm{CO} 2$ is not accompanied by reduced seed quality in Pinus taeda L. Glob. Change Biol. 16, 1046-1056. doi: 10.1111/j.13652486.2009.02007.x

Weber, H., Borisjuk, L., Heim, U., Sauer, N., and Wobus, U. (1997). A role for sugar transporters during seed development: molecular characterization of a hexose and a sucrose carrier in fava bean seeds. Plant Cell 9, 895-908. doi: 10.1105/tpc.9.6.895

Weschke, W., Panitz, R., Gubatz, S., Wang, Q., Radchuk, R., Weber, H., etal. (2003). The role of invertases and hexose transporters in controlling sugar ratios in maternal and filial tissues of barley caryopses during early development. Plant J. 33, 395-411. doi: 10.1046/j.1365313X.2003.01633.x

Weschke, W., Panitz, R., Sauer, N., Wang, Q., Neubohn, B., Weber, H. et al. (2000). Sucrose transport into barley seeds: molecular characterization of two transporters and implications for seed development and starch accumulation. Plant J. 21, 455467. doi: 10.1046/j.1365-313x.2000 00695.x

Westgate, M. E., Schussler, J. R., Reicosky, D. C., and Brenner, M. L. (1989). Effect of water deficits on seed development in Soybean: II. Conservation of seed growth rate. Plant Physiol. 91, 980-985. doi: 10.1104/pp.91.3.980

White, P. J. (2009). Depolarizationactivated calcium channels shape the calcium signatures induced by low-temperature stress. New Phytol. 183, 6-8. doi: 10.1111/j.14698137.2009.02857.x

Whittaker, A., Bochicchio, A., Vazzana, C., Lindsey, G., and Farrant, J. (2001). Changes in leaf hexokinase activity and metabolite levels in response to drying in the desiccationtolerant species Sporobolus stapfianus and Xerophyta viscosa. J. Exp. Bot 52, 961-969. doi: 10.1093/jexbot/52. 358.961

Wilkinson, S., Mills, G., Illidge, R., and Davies, W. J. (2012). How is ozone pollution reducing our food supply? J. Exp. Bot. 63, 527-536. doi: 10.1093/jxb/err317

Will, T., Tjallingii, W. F., Thonnessen, A., and Van Bel, A. J. E. (2007). Molecular sabotage of plant defense by aphid saliva. Proc. Natl. Acad. Sci. U.S.A. 104, 10536-10541. doi: 10.1073/pnas.0703535104

Wingenter, K., Schulz, A., Wormit, A., Wic, S., Trentmann, O.
Hoermiller, I. I., etal. (2010). Increased activity of the vacuolar monosaccharide transporter TMT1 alters cellular sugar partitioning, sugar signaling, and seed yield in Arabidopsis. Plant Physiol. 154, 665-677. doi: 10.1104/pp.110.162040

Wingler, A., Von Schaewen, A., Leegood, R. C., Lea, P. J., and Quick, P. W. (1998). Regulation of leaf senescence by cytokinin, sugars, and light: sefects on NADH-dependent hydroxypyruvate reductase. Plant Physiol. 116, 329-335. doi: 10.1104/pp.116. 1.329

Wippel, K., Wittek, A., Hedrich, R., and Sauer, N. (2010). Inverse $\mathrm{pH}$ regulation of plant and fungal sucrose transporters: a mechanism to regulate competition for sucrose at the host/pathogen interface? PLoS ONE 5:12429. doi: 10.1371/journal.pone.0012429

Wolswinkel, P. (1974). Complete inhibition of setting and growth of fruits of Vicia faba L., resulting from the draining of the phloem system by Cuscuta species. Acta Bot. Neerl. 23, 48-60.

Wolswinkel, P., Ammerlaan, A., and Peters, H. F. C. (1984). Phloem unloading of amino acids at the site of attachment of Cuscuta europaea. Plant Physiol. 75, 13-20. doi: 10.1104/pp.75.1.13

Woodward, F. I. (2002). Potential impacts of global elevated $\mathrm{CO} 2$ concentrations on plants. Curr. Opin. Plant Biol. 5, 207-211. doi: 10.1016/S1369-5266(02)00253-4

Wright, D. P., Baldwin, B. C., Shephard, M. C., and Scholes, J. D. (1995). Source-sink relationships in wheat leaves infected with powdery mildew. II. Changes in the regulation of the Calvin cycle. Physiol. Mol. Plant Pathol. 47, 255-267. doi: 10.1006/pmpp.1995.1056

Wu, L., and Birch, R. G. (2007). Doubled sugar content in sugarcane plants modified to produce a sucrose isomer. Plant Biotechnol. J. 5, 109-117. doi: 10.1111/j.14677652.2006.00224.x

Yang, J., Zhang, J., Wang, Z., Xu, G., and Zhu, Q. (2004). Activities of key enzymes in sucrose-to-starch conversion in wheat grains subjected to water deficit during grain filling. Plant Physiol. 135, 1621-1629. doi: 10.1104/pp.104.041038

Yang, J., Zhang, J., Wang, Z., Zhu, Q., and Liu, L. (2002). Abscisic acid and cytokinins in the root exudates and leaves and their relationship to senescence and remobilization of carbon reserves in rice subjected to water stress during grain filling. Planta 215, 
645-652. doi: 10.1007/s00425-0020789-2

Zakhleniuk, O. V., Raines, C. A., and Lloyd, J. C. (2001). pho3: a phosphorus-deficient mutant of Arabidopsis thaliana (L.) Heynh. Planta 212, 529-534. doi: 10.1007/s004250000450

Zhang, L. Y., Peng, Y. B., PelleschiTravier, S., Fan, Y., Lu, Y. F., Lu, Y. M., et al. (2004). Evidence for apoplasmic phloem unloading in developing apple fruit. Plant Physiol. 135, 574-586. doi: 10.1104/pp.103. 036632

Zhang, W.-H., Zhou, Y., Dibley, K. E., Tyerman, S. D., Furbank, R. T., and Patrick, J. W. (2007). Nutrient loading of developing seeds. Funct. Plant Biol. 34, 314-331. doi: 10.1071/FP06271

Zhang, X. Y., Wang, X. L., Wang, X. F., Xia, G. H., Pan, Q. H., Fan, R. C., et al. (2006). A shift of Phloem unloading from symplasmic to apoplasmic pathway is involved in developmental onset of ripening in grape berry. Plant Physiol. 142, 220-232. doi: 10.1104/pp.106. 081430

Conflict of Interest Statement: The authors declare that the research was conducted in the absence of any commercial or financial relationships that could be construed as a potential conflict of interest.

Received: 13 April 2013; accepted: 02 July 2013; published online: 24 July 2013.

Citation: Lemoine $R$, La Camera $S$, Atanassova $R$, Dédaldéchamp F, Allario T, Pourtau N, Bonnemain J-L, Laloi $M$, Coutos-Thévenot $P$, Maurousset L, Faucher M, Girousse C, Lemonnier P, Parrilla J and Durand M (2013) Sourceto-sink transport of sugar and regulation by environmental factors. Front. Plant Sci. 4:272. doi: 10.3389/fpls.2013. 00272
This article was submitted to Frontiers in Plant Physiology, a specialty of Frontiers in Plant Science.

Copyright (c) 2013 Lemoine, La Camera, Atanassova, Dédaldéchamp, Allario, Pourtau, Bonnemain, Laloi, Coutos-Thévenot, Maurousset, Faucher, Girousse, Lemonnier, Parrilla and Durand. This is an open-access article distributed under the terms of the Creative Commons Attribution License, which permits use, distribution and reproduction in other forums, provided the original authors and source are credited and subject to any copyright notices concerning any third-party graphics etc. 